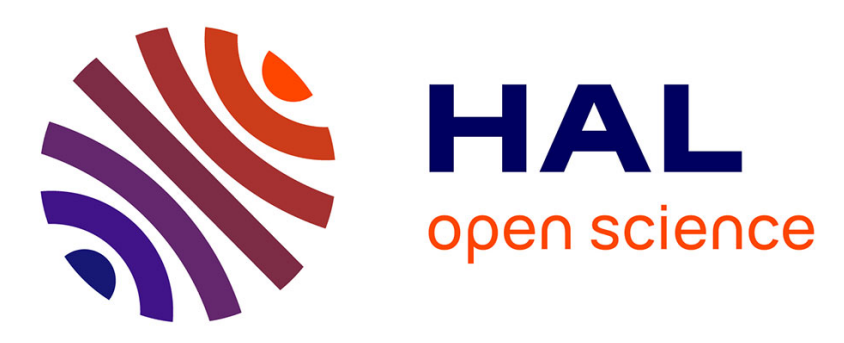

\title{
Challenging the traceability of natural gold by combining geochemical methods: French Guiana example
}

Anthony Pochon, Anne-Marie Desaulty, Laurent Bailly, Philippe Lach

\section{To cite this version:}

Anthony Pochon, Anne-Marie Desaulty, Laurent Bailly, Philippe Lach. Challenging the traceability of natural gold by combining geochemical methods: French Guiana example. Applied Geochemistry, 2021, 129, pp.104952. 10.1016/j.apgeochem.2021.104952 . insu-03199865

\section{HAL Id: insu-03199865 \\ https://hal-insu.archives-ouvertes.fr/insu-03199865}

Submitted on 16 Apr 2021

HAL is a multi-disciplinary open access archive for the deposit and dissemination of scientific research documents, whether they are published or not. The documents may come from teaching and research institutions in France or abroad, or from public or private research centers.
L'archive ouverte pluridisciplinaire HAL, est destinée au dépôt et à la diffusion de documents scientifiques de niveau recherche, publiés ou non, émanant des établissements d'enseignement et de recherche français ou étrangers, des laboratoires publics ou privés. 


\section{Journal Pre-proof}

Challenging the traceability of natural gold by combining geochemical methods:

French Guiana example

Anthony Pochon, Anne-Marie Desaulty, Laurent Bailly, Philippe Lach

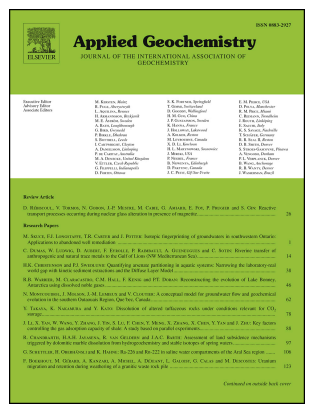

PII:

S0883-2927(21)00084-6

DOI:

https://doi.org/10.1016/j.apgeochem.2021.104952

Reference: $\quad$ AG 104952

To appear in: Applied Geochemistry

Received Date: 30 September 2020

Revised Date: 17 March 2021

Accepted Date: 29 March 2021

Please cite this article as: Pochon, A., Desaulty, A.-M., Bailly, L., Lach, P., Challenging the traceability of natural gold by combining geochemical methods: French Guiana example, Applied Geochemistry, https://doi.org/10.1016/j.apgeochem.2021.104952.

This is a PDF file of an article that has undergone enhancements after acceptance, such as the addition of a cover page and metadata, and formatting for readability, but it is not yet the definitive version of record. This version will undergo additional copyediting, typesetting and review before it is published in its final form, but we are providing this version to give early visibility of the article. Please note that, during the production process, errors may be discovered which could affect the content, and all legal disclaimers that apply to the journal pertain.

(c) 2021 Elsevier Ltd. All rights reserved. 
$1 \quad$ Revised manuscript, version 2

2 Challenging the traceability of natural gold by combining

3 geochemical methods: French Guiana example

4

5 Anthony Pochon ${ }^{1,2 *}$, Anne-Marie Desaulty ${ }^{1}$, Laurent Bailly ${ }^{1}$, Philippe Lach ${ }^{1}$

6

$7 \quad{ }^{1}$ BRGM, F-45060, Orléans, France

$8 \quad{ }^{2}$ Current address: Université d'Orléans, CNRS, ISTO, UMR 7327, F-45071, Orléans, France

$9 *$ To whom correspondence may be addressed. Email: anthony.pochon@cnrs-orleans.fr

10

11

Anthony Pochon (ORCID iD): 0000-0001-7659-9652. 


\section{Abstract}

Considering the high economic importance and worldwide distribution of gold, the ability to identify its provenance is critical and challenging to ensuring a responsible supply chain from deposit to consumer, especially within conflict-affected areas. Here we present an innovative approach to trace the provenance of natural gold from French Guiana through a combination of geochemical and statistical methods. This approach is divided in three steps and allows the identification of illicit gold, the certification of the declared gold origin coming from legal operators and, in some cases, the identification of unknown gold. French Guiana was chosen as a demonstration case of our approach because it is a well-known conflict-affected area where illegal mining is widespread. In the first step, we showed that the use of illegal Hg amalgamation can be easily revealed by looking the gold grain morphology with an optical microscope or by detecting the $\mathrm{Hg}$ with laser-induced breakdown spectroscopy that allow direct detection on the field. In the second and principal step, we demonstrated that a declared provenance of gold can be certify with a high degree of confidence by measuring the $\mathrm{Ag}$ content of a gold grain population and by checking it against a database with the Kolmogorov-Smirnov statistic. In the final step that allows the identification of the origin of unknown gold, we used (i) the content of minor elements $(\mathrm{Cu}$ and $\mathrm{Hg})$, (ii) the identification of mineral inclusions and their relative proportions within samples and (iii) the trace element composition of natural gold grains determined by LA-ICP-MS and coupled with a permutational multivariate analysis of variance and a similarity percentage analysis. This method allows the identification of the provenance of $69 \%$ of the gold samples; the provenance of other gold populations ( $31 \%)$ cannot be identified because of their geological similarity with other groups. The traceability of natural gold can be guaranteeing with our innovative approach, in particular by certifying declared gold population provenance. Further challenges to be addressed will be the implementation of such approach in others conflict-affected regions to support the global supply chain of gold.

\section{Keywords}

Gold, Geochemistry, Traceability, Statistical test, French Guiana 


\section{Introduction}

\section{1}

As one of the oldest and most important precious metals worldwide, gold holds high economic importance globally. It has long been traded within both legal and illegal supply chains, which are often closely intertwined because gold is an easy metal to recover. Even though many major mining companies have turned to large primary deposits, a significant amount of gold is still produced by artisanal and small-scale operations on secondary eluvial and alluvial deposits. The latter, when illicit, are responsible for the majority of the extensive and detrimental deforestation, as well as most of the mercury $(\mathrm{Hg})$ pollution in soils and water (Goix et al., 2019), human trafficking, and ecosystem destruction (Carisch, 2012). Coupled with the funding of organized crime and terrorism, illegal gold mining is a global problem (Darlington, 2018).

Due to pressure from civil society, major importing countries have imposed certified supply chain restrictions that follow the principles of due diligence. The American law known as the "Dodd-Frank Act" includes a condition that requires companies using gold, tin, tungsten and tantalum to make efforts to determine if those materials came from Democratic Republic of Congo (DRC) or an adjoining country. If so, it requires a due diligence review of their supply chain to determine whether their mineral purchases are being used to fund armed groups in DRC (United States Congress, 2010). Following the American example, the European Parliament and Council adopted EU Regulation 2017/821, which sets forth supply chain due diligence obligations for Union importers of tin, tantalum, tungsten and gold originating from conflict-affected and highrisk areas (European Parliament and Council, 2017). This regulation, effective January 1, 2021, implements the principles of the OECD Due Diligence Guidance at the community level to achieve responsible supply chains for minerals (OECD, 2016). It obliges the mineral- and metal-importing industry to set up a chain of custody or a traceability system for their supply chains.

Currently, there are two principal ways to ensure traceability of minerals within the due diligence process: (i) checking the chain-of-custody systems, based on the shipping documentation ("bagging and tagging" information) that is included in online databases to allow real-time mineral tracking and electronic tagging; and (ii) analytical fingerprints, based on intrinsic signatures of raw or treated minerals. These two methods are independent yet complementary. The former is inexpensive and easy to implement on a large scale but does require additional information to be attached to shipments, which are susceptible to fraud. To date, the second method appears too onerous for systematic use, but it does reinforce the first by providing some control. 
The German Federal Institute for Geosciences and Natural Resources (BGR) has developed an analytical fingerprint of coltan ore using a multi-method approach, which was used to verify and audit the traceability system based on documentation established in DRC (Melcher et al., 2008). The traceability of heterogenite from the DRC was investigated through the Trace project (“TRACeability of hEterogenite”; Decrée et al., 2015). Similarly, several studies have been conducted to investigate compositional profiles of gold. Quantitative analysis of gold by trace element determination has been performed since the 1960s (Stumpfl and Clark, 1965; Desborough, 1970). Most of the studies used EPMA results for petrological information about gold formation, as a tool for gold exploration (Desborough et al., 1971; Guisti and Smith, 1984; Chapman et al., 2000b) or for provenancing archeological gold artifacts (Chapman et al., 2006). These studies mainly focus on Ag content because it is the only element systematically present in any gold alloy and it is homogeneous within intra-particle (i.e. in the grain core). Trace element profiling of gold, which is the most common technique, has been used to help distinguish legal from illegal gold (Roberts et al., 2016) and to identify the source of the latter (Watling et al., 1994, 2014; Dixon and Merkle, 2019). The technique consists of quantifying the trace-level components within gold matrices by laser ablation inductively coupled plasma mass spectrometer (LA-ICP-MS) and is mainly based on the assertion that gold will inherit a unique trace element signature related to specific geological (e.g. hydrothermal or metamorphic event) and extractive processes (Roberts et al., 2016). It is important to note that composition of gold is generally heterogeneous at sub- $\mu \mathrm{m}$ level (Chapman et al. 2021), which makes the use of multivariate data more challenging. The previous traceability studies only focus on the identification of processed and/or refined non-natural gold (i.e. bullion, jewelry, commercial alloys and melted seized gold bars).

In their pioneering study funded by the World Wildlife Fund for Nature (WWF), Augé et al. (2015) used for the first time a combination of minor elements compositions in gold matrices and the nature of microinclusions in gold crystals to determine the origin of four gold samples from French Guiana. Recently, Pochon et al. (2020) used the Ag distribution in a population of gold grains to identify the origin of natural gold samples from French Guiana and it assessed the reliability of a field tool (i.e. handheld laser-induced breakdown spectroscopy, LIBS) as an alternative of the classical laboratory tool (i.e. electron microprobe, EPMA). The two previous studies in French Guiana have demonstrated their ability to partially trace the provenance of some limited number of gold occurrences and to distinguish legal from illegal natural gold. Indeed, $\mathrm{Hg}$ is used in small-scale mining to rapidly extract gold from ore as a stable amalgam in the gold recovery process. The recovered gold contains several wt\% Hg (Augé et al., 2015; Legg et al., 2015; Goix et al., 2019). Using Hg 
content to distinguish illegal versus legal gold has been effective in French Guiana since the use of mercury was banished in France on January 1, 2006 by prefectoral order. Although nowadays amalgamation is not considered illegal in all countries, the ratification of the Minamata Convention on Mercury (i.e. guidelines to avoid the use of $\mathrm{Hg}$ ) by 126 countries as of December 16, 2020, should tend to eliminate the use of $\mathrm{Hg}$ for recovering gold. The ever-increasing number of extraction sites and commercial exchanges requires a more robust and efficient approach.

Thus, we propose an innovative approach to ensure the traceability of natural gold that combine mineralogical (optical and scanning electron microscopy), geochemical (EPMA, LIBS and LA-ICP-MS) and statistical (Kolmogorov-Smirnov statistic, permutational multivariate analysis of variance and a similarity percentage analysis) methods. Although similar in many ways, the remit of our approach is distinct to those used for gold compositional studies that investigate responsible ore forming processes for improving gold exploration or the understanding of gold metallogeny, and that requires a strong geological knowledge for tracing the hydrothermal history. Here, we provide practical and workable tools for verifying the provenance of natural gold in order to speed up the decision-making. They could play an essential role in the due diligence certification systems and demonstrate responsible sourcing, especially within conflict-affected areas where illegal gold mining is common. In order to performed and assess our proposed approach, the French Guiana was chosen as a perfect demonstration case because it is well-known conflict-affected area due to widespread illegal gold mining leading to mercury pollution and deforestation of Amazon rainforest.

\section{The nature of French Guiana gold}

The French Guiana is part of the large Guiana Shield of about $900,000 \mathrm{~km}^{2}$, covering the northern part of Brazil, the eastern part of Columbia, the eastern part of Venezuela and the Guyana, the Surinam and the French Guiana. In spite of the existence of important mineral resources (gold, petroleum, niobium, tantalum, bauxite, kaolinite), only few easily accessible publications have been produced on the geology and economic potential of the French Guiana, most of the existing data being part of the Bureau de Recherches Géologiques et Minière (BRGM) internal reports (e.g. Milési et al., 1995; Vanderhaeghe et al., 1998; Delor et al., 2003). Gold deposits are mainly located in the mid-north part of the French Guiana (Fig. 1). They are mainly hosted by the Paleoproterozoic Paramaca Greenstone Belt that is interpreted as the remnant of a volcanic arc sequence formed during the Transamazonian orogeny. It forms two regional-scale synform structures located to the north and south of the 
126

127

128

129

130

131

132

133

134

135

136

137

138

139

140

141

142

143

Mesorhyacian Central TTG (Tonalite Trondhjemite Granodiorite) complex (Delor et al., 2003; Enjolvy, 2008).

Four types of primary gold deposits have been identified (Marcoux and Milési, 1993; Milesi et al., 1995, 2003; Franklin et al., 2000; Guiraud et al., 2020): (i) gold-rich volcanogenic massive sulphide (VMS, e.g. Montagne d'Or); (ii) stratiform/stratabound gold deposits hosted by volcano-sedimentary rocks, where gold is associated with disseminated sulphides (e.g. Dorlin); (iii) gold-bearing polygenic conglomerates with disseminated gold (e.g. Montagne Tortue); and (iv) orogenic gold deposits which consist of quartz-carbonate-sulphides veins and stockworks (e.g. Yaou, Esperance, Camp Caïman), essentially hosted by volcano-sedimentary rocks and granitoids. The primary gold deposits discussed in this study (Dagobert, Repentir, Mataroni, Saint Elie and Doyle) belong to the orogenic type. It is important to note that the VMS deposits remain rare and that goldbearing conglomerates and stratabound gold deposits are mostly overprinted by late orogenic gold event (Marcoux and Milési, 1993; Milési et al., 2003), making the orogenic gold the most frequent in French Guiana. Most gold deposits are hosted in Paleoproterozoic greenstone belts (Cassard et al., 2008), and consequently share several affinities such as fluid composition, the nature of the host rocks and the source of the metals (Goldfarb and Groves, 2015). Nevertheless, most of the gold production of the French Guiana is coming from placers of Pliocene to Quaternary age explaining that this type of deposit is the most illegally extracted and consequently represent the major part of samples in this study. In most cases, placer gold deposits are thus mainly composed of gold grains coming from primary orogenic gold deposits and may have one or several contributing sources. 


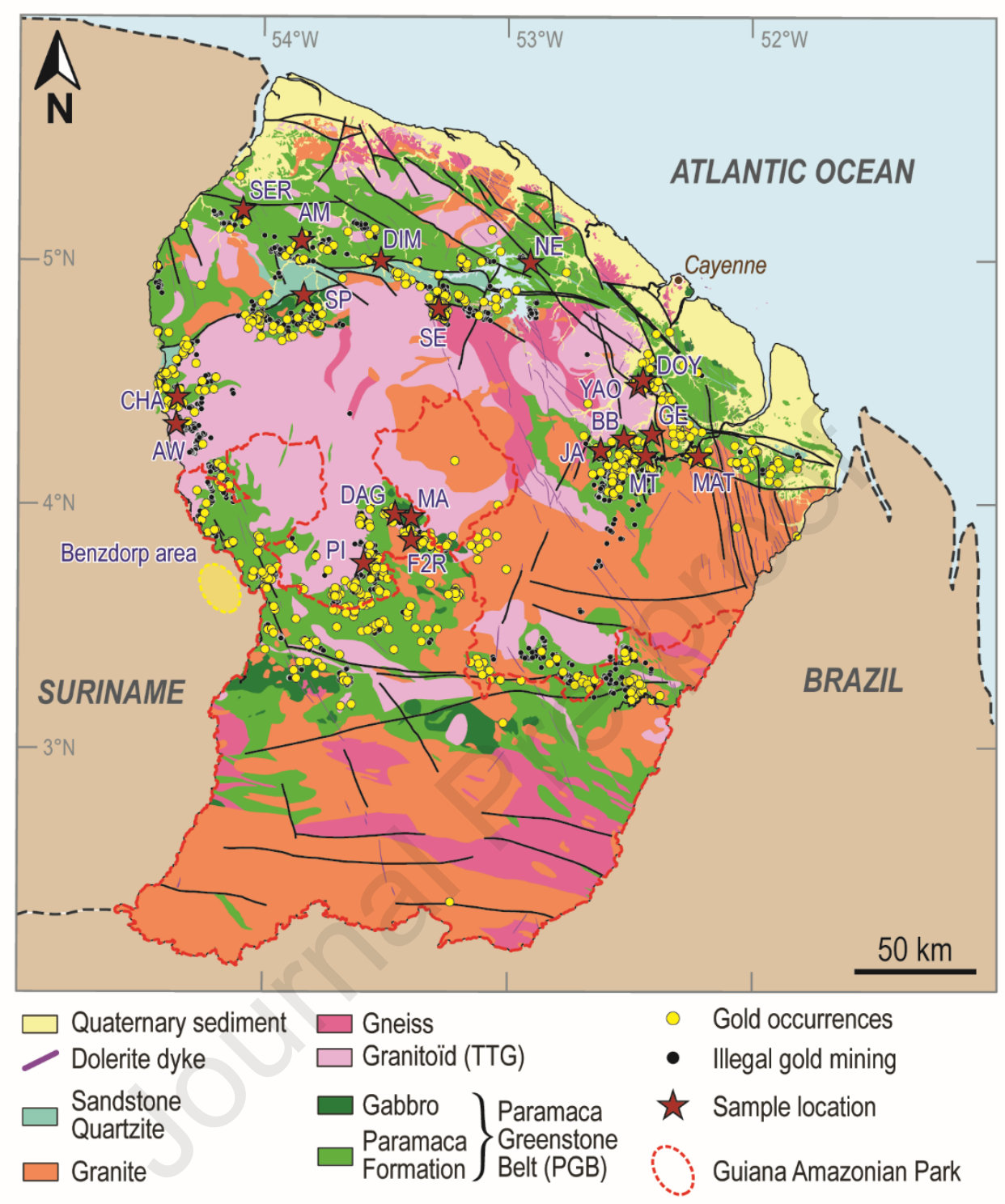

Fig. 1 Simplified geological map of French Guiana showing the main lithostructural framework and location of gold populations, including those from Suriname (Benzdorp area). Red stars correspond to the sample location used in this study. Gold populations: AM, Amadis; AW, Awa ; BB, Bois Bandé; DIM, Dimanche; GE, Grillon Est; JA, Jalbot; NE, Nelson; PI, Petit Inini; SP, Saint Pierre; SER, Serpent; CHA, Chantal; YAO, Yaoni; MAT, Mataroni; F2R, F2 Repentir; DAG, Dagobert; SE, Saint-Elie; SE(SA), Saint-Elie (Saint-Auguste); DOY, Doyle; MT, Montagne Tortue; MA, Marc.

\section{Sampling and methods}


The natural gold used for this study consists of 69 samples from 21 gold populations and comes from the French

Guiana and in a lesser extent from Suriname (Fig. 1). The view was taken to remain anonymous the samples

origin to avoid the disclosure of their geochemical signatures (Table 1). Only 6 populations (i.e. 13 samples) are

from primary deposits, the remainder being alluvial in origin (i.e. 15 populations and 56 samples). This limited and were used as a reference for illegal gold (Kio-A-Sen et al., 2016). Sixteen samples previously studied by Augé et al. (2015) as part of a project funded by the WWF to test the feasibility of the analytical traceability of gold from French Guiana were re-analyzed in this study. Each sample consists of about 20-40 individual gold grains between 0.05 and $3 \mathrm{~mm}$ across, embedded in epoxy resin blocks and polished to expose the core of the gold grains. Overall, some 2200 gold grains were used for this study.

Table 1. Description of the samples from French Guiana gold populations. Number of studied gold grains within brackets

\begin{tabular}{|c|c|c|c|}
\hline Gold population group & Region & Type of gold & Sample name \\
\hline A & French Guiana & Primary & A1 (41), A2 (58) \\
\hline $\mathrm{B}$ & French Guiana & Primary & B1 (56) \\
\hline C & French Guiana & Primary & C1 (62), C2 (44), C3 (52) \\
\hline$D$ & French Guiana & Alluvial & D1 (42), D2 (16), D3 (18) \\
\hline$E$ & French Guiana & Alluvial & E1 (47), E2 (28) \\
\hline $\mathrm{F}$ & French Guiana & Alluvial & F1 (34) \\
\hline G & French Guiana & Alluvial & G1 (26), G2 (21), G3 (36) \\
\hline $\mathrm{H}$ & French Guiana & Alluvial & H1 (31), H2 (28) \\
\hline 1 & French Guiana & Alluvial & I1 (29), I2 (25), I3 (25), I4 (26) \\
\hline $\mathrm{J}$ & French Guiana & Alluvial & J1 (35), J2 (15) \\
\hline $\mathrm{K}$ & French Guiana & Alluvial & $\mathrm{K} 1(26)^{1}, \mathrm{~K} 2(27)^{1}, \mathrm{~K} 3(34)$ \\
\hline$L$ & French Guiana & Primary & L1 (15), L2 (34) \\
\hline M & French Guiana & Alluvial & $\begin{array}{c}\text { M1 (23), M2 (34), M3 (30), M4 (28), } \\
\text { M5 (30), M6 (31) }\end{array}$ \\
\hline $\mathrm{N}$ & French Guiana & Alluvial & $\begin{array}{l}\text { N1 (22), N2 (31), N3 (30), N4 (29), } \\
\text { N5 (29), N6 (29), N7 (33), N8 (40) }\end{array}$ \\
\hline $\mathrm{O}$ & French Guiana & Alluvial & $\mathrm{O} 1(31), \mathrm{O} 2(35)$ \\
\hline $\mathrm{P}$ & French Guiana & Alluvial & $\begin{array}{c}\text { P1 (31), P2 (40), P3 (28), P4 (31) } \\
\text { P5 (35) }\end{array}$ \\
\hline Q & French Guiana & Alluvial & Q1 (29), Q2 (32), Q3 (31) \\
\hline $\mathrm{R}$ & French Guiana & Alluvial & R1 (39), R2 (30), R3 (35), R4 (31) \\
\hline $\mathrm{T}$ & French Guiana & Primary & T1 (20), T2 (22), T3 (9), T4 (30) \\
\hline
\end{tabular}




\begin{tabular}{cccc} 
U & French Guiana & Alluvial & U1 (25), U2 (20), U3 (46), U4 (14) \\
\hline Surinam & $\begin{array}{c}\text { Benzdorp } \\
\text { (Surinam) }\end{array}$ & Amalgam & S1 (42), S2 (16), S3 (18), S4 (31), \\
& S5 (34)
\end{tabular}

${ }^{1}$ samples declared as alluvial gold whereas it is amalgam gold and ${ }^{2}$ primary gold sample from $U$ group

\subsection{Mineral chemistry using quantitative electron microprobe analysis}

172

Quantitative analyses were carried out on gold grains using a Cameca SX-Five electron probe micro-analyzer (EPMA) at the ISTO-BRGM laboratory (Orléans, France) (Appendix A.1). The major and minor elements analyzed were $\mathrm{Au}, \mathrm{Ag}, \mathrm{Cu}, \mathrm{Pd}$ and $\mathrm{Hg}$. Pure cinnabar standards were used for $\mathrm{Hg}$, whereas pure metals were used for the other elements. Each analysis was performed on the core of a gold grain which better reflect the primary signature of the grain, the composition of the rims of alluvial gold particles being modified by subsurface conditions (Groen et al., 1990). Run conditions were an accelerating voltage of $20 \mathrm{kV}$, a beam current of $40 \mathrm{nA}$, and counting times of $30 \mathrm{~s}$ on-peak and $15 \mathrm{~s}$ background.

\subsection{Mercury measurements using a handheld LIBS analyzer}

The needs of fast and real-time measurements on the field led us to use a direct method for the Hg detection. Mercury analyses were carried out using a commercial SciAps $\odot$ Z-200 C+ handheld laser-induced breakdown spectroscopy (LIBS) analyzer. Its portability and broad spectral range (i.e. 190-625 nm) make it a suitable tool for real-time measurements in the field or a field laboratory (Connors et al., 2016; Harmon et al., 2017). Spectrometers are calibrated daily by ablating a piece of stainless steel inside the LIBS system in order to correct spectral shifts. Each analysis was performed under constant argon flow with a pressure of 10 psi. All the raw LIBS data were divided by the signal intensity of the Au emission line at $479.24 \mathrm{~nm}$, which represents the matrix-dominant element and consequently the maximum signal intensity. To assess the performance of the instrument, about 500 LIBS analyses were performed on gold grains. They come from 5 French Guiana gold populations legally extracted by small-scale artisanal miners and 3 Suriname populations extracted by $\mathrm{Hg}$ amalgamation. Each single-shot consists of 8 cleaning (laser) pulses to ensure tape breakthrough, followed by the collection of 32 averaged spectra at the same location to minimize the affected surface area on the gold grains (due to their small size) and to avoid striking mineral inclusions. 


\subsection{Identification of mineral micro-inclusions}

A reflected light optical microscope and a scanning electron microscope (SEM) were used to locate and identify the nature of mineral inclusions within the gold alloy. The use of an SEM-EDS (energy dispersive X-ray spectrometer coupled with an SEM) is strongly recommended considering the small size of the micro-inclusions in the gold grains. More than half (58\%) of the micro-inclusions are less than $10 \mu \mathrm{m}$. In addition, the intense optical reflectance of gold affects the classical reflectance of the inclusions. The SEM observations were carried out on a tabletop Hirox SH-3000 SEM with a $20 \mathrm{kV}$ voltage and coupled to a Bruker-AXS EDS system.

\subsection{Quantitative analysis of trace elements using LA-ICP-MS}

Trace element concentrations were determined in situ using the laser ablation inductively coupled plasma mass spectrometer (LA-ICP-MS) at the BRGM laboratory (Orléans, France). The following isotopes were monitored: ${ }^{33} \mathrm{~S},{ }^{48} \mathrm{Ti},{ }^{52} \mathrm{Cr},{ }^{55} \mathrm{Mn},{ }^{57} \mathrm{Fe},{ }^{58} \mathrm{Ni},{ }^{59} \mathrm{Co},{ }^{63} \mathrm{Cu},{ }^{64} \mathrm{Zn},{ }^{75} \mathrm{As},{ }^{76} \mathrm{Se},{ }^{78} \mathrm{Se},{ }^{82} \mathrm{Se},{ }^{103} \mathrm{Rh},{ }^{105} \mathrm{Pd},{ }^{106} \mathrm{Pd},{ }^{107} \mathrm{Ag},{ }^{109} \mathrm{Ag},{ }^{112} \mathrm{Cd}$, ${ }^{114} \mathrm{Cd},{ }^{118} \mathrm{Sn},{ }^{120} \mathrm{Sn},{ }^{121} \mathrm{Sb},{ }^{123} \mathrm{Sb},{ }^{130} \mathrm{Te},{ }^{195} \mathrm{Pt},{ }^{197} \mathrm{Au},{ }^{202} \mathrm{Hg},{ }^{208} \mathrm{~Pb},{ }^{209} \mathrm{Bi}$. Sulfur $\left({ }^{33} \mathrm{~S}\right)$ was monitored to avoid signal interference of sulphide inclusions, whereas ${ }^{57} \mathrm{Fe}$ and ${ }^{48} \mathrm{Ti}$ were used to avoid signal interference from $\mathrm{Fe}-\mathrm{Ti}$ oxide inclusions. Gold $\left({ }^{197} \mathrm{Au}\right)$ was monitored to verify that the ablated matrices comprised only gold.

The BRGM's LA-ICP-MS system consists of a CETAC Excite excimer laser (193 nm) coupled to a ThermoScientific XSERIES 2 quadrupole inductively coupled plasma mass spectrometer (ICP-MS). The laser is equipped with a HelEx® 2 volume ablation cell, which optimizes the material transport to the ICP-MS. The ablated material is carried by He, which is then mixed with $\mathrm{N} 2$ and Ar, before injection into the plasma source. The instrument was aligned, and mass calibration performed before each analytical session on the NIST SRM 612 reference glass. A beam diameter of $85 \mu \mathrm{m}$ was used to enhance the signal and reach very low detection limits for analyzed trace elements. Ablation areas were carefully selected because a wide beam diameter increases the chances of ablating solid micro-inclusions or ablating part of the modified rim in small gold grains. A single analysis consists of $20 \mathrm{~s}$ of gas blank followed by $40 \mathrm{~s}$ of ablation. A repetition rate of $8 \mathrm{~Hz}$ and a laser beam energy of $3.06 \mathrm{~J} / \mathrm{cm} 2$ were used during analyses.

Quantification of gold was carried out using ${ }^{107} \mathrm{Ag}$ as the internal standard. The Ag content were determined by EPMA. For each analytical session, we used the following bracketing procedure: one analysis of the RAuP7 and RAuP3 gold reference materials from MBH for every 10 gold grain analyses, and one analysis of NA-Au-31 and NA-Au-30 (Kovacs et al., 2009; Milidragovic et al., 2016) for every 20 analyses. This sequence was repeated up 
224

to the end of the session. $\mathrm{Ni}, \mathrm{As}, \mathrm{Cd}, \mathrm{Sn}$ and Te were calibrated using reference material NA-Au-31. The remaining elements were calibrated using RAuP7. Reference materials NA-Au-30 and RAuP3 were used to monitor the quality of analyses. They were treated as unknowns to control the reproducibility and accuracy of analyses. Data reduction was carried out using Iolite software (Paton et al., 2011). Analyses of RAuP3 show high accuracy and very good precision, with a mean relative difference (RD) of $\sim 4 \%$ and a relative standard deviation (RSD) of $\sim 8 \%$ for all considered elements (Appendix A.2). Isotopes ${ }^{121} \mathrm{Sb}$ and ${ }^{208} \mathrm{~Pb}$ were slightly overestimated by $12-14 \%$ and were also slightly heterogeneous, with an RSD of $14-16 \%$. Note that ${ }^{209} \mathrm{Bi}$ has the largest RSD of $18 \%$. The NA-Au-30 analyses show good accuracy and very good precision, with a mean RD of $\sim 12 \%$ and a mean RSD of $\sim 8 \% .{ }^{114} \mathrm{Cd}$ and ${ }^{118} \mathrm{Sn}$ are underestimated by $25 \%$ (Appendix A.2). Chapman et al. (2021) have highlighted that trace elements can be heterogeneously distributed within a gold particle at 5-10 $\mu \mathrm{m}$ scale. But our LA-ICP-MS analytical conditions, that use a larger ablation spot $(85 \mu \mathrm{m})$, yielded reproducible analyses within a same gold particle, meaning that our gold grains can be considered as homogeneous at the scale of our ablation spot.

\subsection{Statistical tests}

The empirical distribution functions and the Kolmogorov-Smirnov (KSD), the maximum distance between two empirical cumulative distribution functions (CDFs), was used to characterize and compare the distribution of $\mathrm{Ag}$ content among different samples. It was chosen for its widespread use in raw material traceability studies, such as coltan, tin, tungsten and gold (Gäbler et al., 2013, 2017, 2020; Martyna et al., 2018; Pochon et al., 2020). Indeed, the KSD is used as a measure of similarity between two samples by comparing their CDFs. Having the same distribution does not necessarily prove that two samples have the same origin, but we take sides here that samples are considered as coming from the same population when they share the same distribution, as many authors does (e.g. Sheskin, 2011). Therefore, a small KSD value indicates a high degree of similarity, whereas a large KSD value rather reflects a low degree of similarity. To conclude whether if a KSD value between two individual samples is the result of common origin between two samples, a decision-making criterion is needed. In this study, two approaches are used for assessing the relevance of KSD statistics, (i) the "classical" KS test (Kolmogorov, 1933; Smirnov, 1939; Massey, 1951) and (ii) the approach developed by Gäbler et al. (2017), that we renamed KS17 approach for avoiding confusing with the KS test. 

consider two CDFs as significantly different) as a decision criterion. If KSD is less than D critical and if the pvalue (i.e. value of probability) is higher than the level of significance $(\alpha)$, then the "null hypothesis" (i.e. two samples have the same distribution) cannot be rejected, and the two samples are considered to be from the same origin. For this study, $\alpha=0.05$. This commonly used value gives a confidence degree of $1-\alpha(95 \%)$. D critical is dependent on sample size and the level of significance (Smirnov 1939), indeed, a low sample size yields a higher D critical. The KS17 approach uses an empirically-deduced decision criterion based on KSD values for all possible comparisons of reference samples from a given mine site and calculated as follows:

$$
D C=\mathrm{X}+3 \sigma
$$

where DC is the decision criterion, $\mathrm{X}$ is the mean and $\sigma$ is the standard deviation calculated from the KSD values. When this empirically decision criterion is applied, samples are considered to originate from the declared origin if their KSD value is smaller than the DC when compared to the single reference samples of the declared origin. This deposit-specific DC is dependent on the number of references samples from the same mine site. Therefore, this method is not suitable when only two or three reference samples are available from the same mine site due to the low number of computed KSD values. However, in the case where the studied mine site has a low number of reference samples, a standard DC can be derived by taking into account all others available mine sites with at least two reference samples. KSD values are thus calculated for all reference sample pairs from common mine sites and the DC is calculated as given in Equation (1), but, with $\mathrm{X}$ as the mean of all KSD values of reference sample pairs with common origin but not related to any reference sample coming from the studied mine site (Gäbler et al., 2017, 2020).

LA-ICP-MS datasets contain non-detected values that are below the detection limit. They are thus censored compositional data that cannot be considered as continuous data and must be transformed before any statistical analyses (Aitchison, 1982; Helsel, 2011). Before performing multivariate statistical analyses and to avoid "fabricating" data by replacing values below the detection limit with arbitrary values, we chose to rank values by a nonparametric method after censoring at the highest detection limit following the recommendations of Helsel (2011). Ranking was only applied to data of gold populations that are compared between them, meaning that the obtained rank values for data from three compared gold populations (e.g. groups A, B and C) will be different from the obtained rank values for data from other gold populations (e.g. groups D, E and F). Thus, all considered values are ranked and the attributed rank for data below the detection limit is specific for 
281

each considered element and each samples comparison. Permutational multivariate analysis of variance (PERMANOVA), a nonparametric multivariate statistical test (Anderson, 2001, 2017), was used to compare different gold populations using their trace element compositions. Although originally used in ecological studies, this test is now used across many fields such as chemistry, social sciences, environmental sciences, and more recently in geochemistry (Monnier et al., 2018, 2021; Launay et al., 2021). PERMANOVA is a geometric partitioning of multivariate data using a dissimilarity measure (e.g. Bray-Curtis distance). It quantifies the dissimilarity between each sample of one group (i.e. gold population in our case) considering element concentration and test the null hypothesis that the centroids and dispersion were equivalent for each sample comparison, using a pseudo F-ratio constructed by inter-point geometric approach (scalar correlations based on the distance measure), such as:

$$
\left(S S_{A} / S S_{R}\right) \times(N-g / g-1)
$$

where $\mathrm{SS}_{\mathrm{A}}$ (among-group sum-of-squares) is the sum of the squared distances from individual group centroids to the overall centroid, $\mathrm{SS}_{\mathrm{R}}$ (within-group sum-of-squares) is the sum of the squared distances to centroids from individual sampling units to their own group centroid, $N$ is the total number of observations, and $g$ is the number of groups. PERMANOVA assumes only the exchangeability of the dataset under a true null hypothesis. In this study, PERMANOVA was used to relate gold samples to their provenance, when the Ag content distribution was not sufficient to distinguish the distinct origins. The rejection of the null hypothesis (i.e. a p-value lower than 0.05) means that the trace element composition differs between the groups compared. The distance measure was calculated with the Bray Curtis dissimilarity index (Bray and Curtis, 1957), which is better at taking into account the absence or presence of an element than the classical Euclidian index, and consequently is better suited for ordinal data. The smaller the pseudo-F ratio, the more the two compared populations share similarities. A ratio equal or lower than 1 is traditionally taken to mean that the populations are indistinguishable, because it indicates that among-group distances $\left(\mathrm{SS}_{\mathrm{A}}\right)$ are equal or lower than within-group distances $\left(\mathrm{SS}_{\mathrm{R}}\right)$. The significance of the variables was tested and obtained by 9999 permutations (Anderson, 2001). Similarity percentage analysis (SIMPER; Clarke, 1993) was performed to determine the contribution of each trace element. Indeed, it calculates the contribution of each trace element to the dissimilarity between each two groups, using the Bray-Curtiss dissimilarity matrix. This allows the identification of variables that are likely to be the major contributors to any difference between groups detected by PERMANOVA. All statistical analyses were performed using a combination of software such as XLSTAT, PAST 4.02 (Hammer et al., 2001) and R. 


\section{Results and Discussion}

312 The steps in our multi-method analytical approach to gold traceability answer three guiding questions (Fig. 2).

313 The first is "Has mercury been used to extract the gold?". This step aims to identify gold grains illegally 314 extracted by Hg amalgamation that should not be allowed in the supply chain. The second is, "Does the gold 315 correspond to its presumed provenance?". This step uses the statistical distribution of silver (Ag) in gold grains 316 and is considered the most discriminative way to certify gold population provenance declared by owners. The 317 third question is, "What is the origin of unknown gold?". This last step aims to identify the origin of gold from 318 dubious sources (i.e. seized gold) by looking at the minor and trace element composition and the mineral 319 inclusion assemblage, in addition to the statistical distribution of Ag. This question is especially relevant in the 320 case of gold without declared origin, gold diverted from the legal supply chain or gold seized by authorities 321 when combating illegal gold mining operations. 


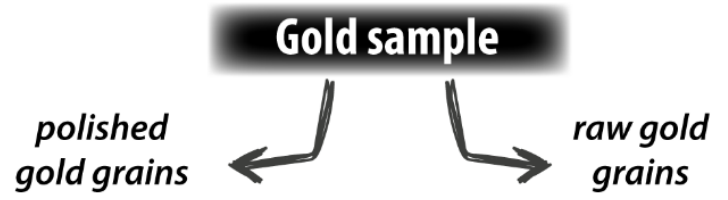

\section{(1) Has mercury been used to extract the gold?}

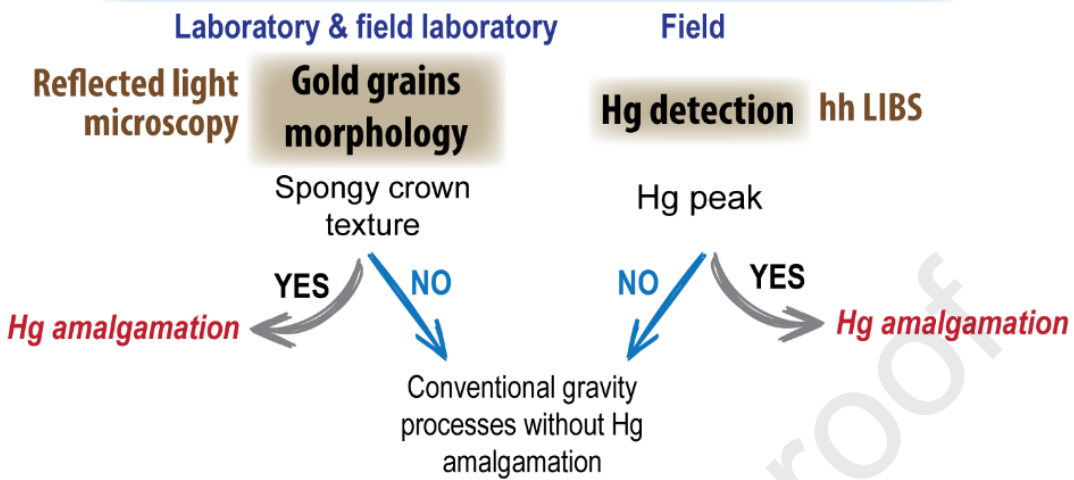

\section{Certifying gold origin}

(2) Does the gold correspond to its presumed provenance?

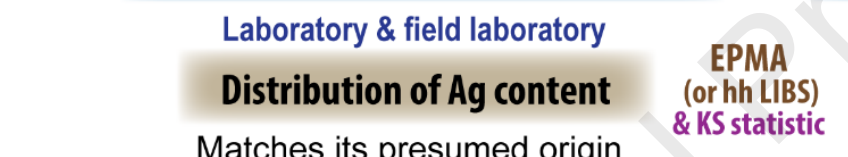

Identifying gold origin

(3) What is the origin of unknown gold?

Laboratory \& field laboratory

Distribution of Ag content

Matches only one gold population

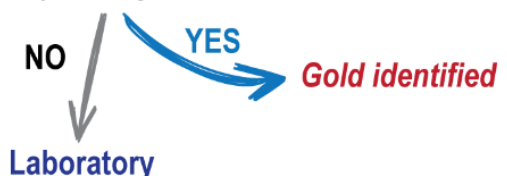

Sequence of techniques to use

\begin{tabular}{|c|c|c|}
\hline $\begin{array}{l}\mathrm{Hg} \text { and/or } \mathrm{Cu} \\
\text { content }\end{array}$ & $\begin{array}{l}\text { Mineral } \\
\text { inclusions }\end{array}$ & $\begin{array}{l}\text { Trace element } \\
\text { composition }\end{array}$ \\
\hline EPMA & $\begin{array}{l}\text { SEM-EDS } \\
\text { EPMA }\end{array}$ & $\begin{array}{l}\text { LA-ICP-MS } \\
\text { \& PERMANOV/ }\end{array}$ \\
\hline
\end{tabular}

Matches only one gold population

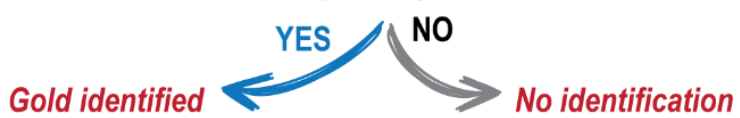

Fig. 2 Overview of the multi-method approach for the traceability of natural gold. This approach is based on the analytical fingerprint of gold grains, and the steps answer three guiding questions as part of the due diligence process. "hh" correspond to handheld. See text for further explanations.

\subsection{Reliable and efficient ways to identify extracted gold with mercury} process. The recovered gold contains several wt\% Hg (Augé et al., 2015; Legg et al., 2015; Goix et al., 2019). 
331

By taking advantage of the known physicochemical properties of gold (Giusti, 1986; Grant et al., 1991; Townley et al., 2003; Youngson et al., 2002; Márquez-zavalía et al., 2004) and because the use of mercury in gold mining is prohibited in France, we propose two easy methods to quickly identify gold recovered by the $\mathrm{Hg}$ amalgamation process, namely simple reflected light optical microscopy in the laboratory and a handheld LIBS analyzer in the field.

\subsubsection{Gold grain morphology: a source of easy-to-use information}

Although the information on gold grain morphology is not considered a discriminating factor for traceability, it can be very useful, as a first check, for identifying the type of gold grains. Three main types of gold are easily recognizable in French Guiana: primary gold mined from bedrock deposits, alluvial gold mined from the erosional products of former bedrock deposits, and gold from either source recovered using mercury. Primary gold grains are characterized by an irregular outline composed of angular edges, embayments and primary crystal imprints (Fig. 3a). In contrast, alluvial gold grains exhibit a rounded habit and more yellowish rims related to natural Ag-depletion under depositional and transport conditions (Fig. 3b). Primary and alluvial gold grain populations thus constitute two different types of gold that must be compared separately. Among the samples of polished gold grains studied by optical microscopy, gold amalgams have the most noticeable morphological characteristics compared to classic primary and alluvial gold. They invariably exhibit a light yellowish and highly porous alloy induced by the evaporation of mercury, typical of the so-called spongy crown texture (Fig. 3c and d). This texture has been observed in almost all the gold grains recovered by $\mathrm{Hg}$ amalgamation from the neighboring Suriname artisanal mines (Augé et al. 2015), highlighting this feature as a major indicator of illegally extracted gold in French Guiana. Some natural alluvial gold grains may exhibit a similar texture acquired during natural processes (Fig. 3e), but they can be easily distinguished by studying samples of polished gold grains under an optical microscope. Gold amalgams have a rim with a light-yellow color whereas natural grains have a rim of pure gold with a dark yellow color. Furthermore, the spongy crown texture of gold amalgams is the result of porosity (i.e. empty holes that were created by the vaporization of $\mathrm{Hg}$ (Fig. 3f)), whereas such a texture in natural grains results from overgrowth with other minerals that have since partially eroded away (e.g. Fe-oxides; Fig. 3e). Although the presence of spongy crown texture may also be of natural origin due to cinnabar reduction (Youngson et al., 2002), this natural process remain scarce. When a sample only consist of gold with such spongy crown textures, it is more likely that the presence of $\mathrm{Hg}$ was 
anthropogenic. In our dataset, two samples (samples K1 and K2) from the group K containing only amalgams

361 were excluded from the traceability process. Among the other samples, only 12 grains $(<1 \%$ of the dataset) with amalgam morphologies were identified. The very low proportion of gold amalgams in the studied samples

363 suggests they were mined without use of mercury amalgamation, and the mercury is likely either natural in origin or the result of inheritance due to nearly 150 years of $\mathrm{Hg}$ amalgamation use before its banishment in 2006 . 

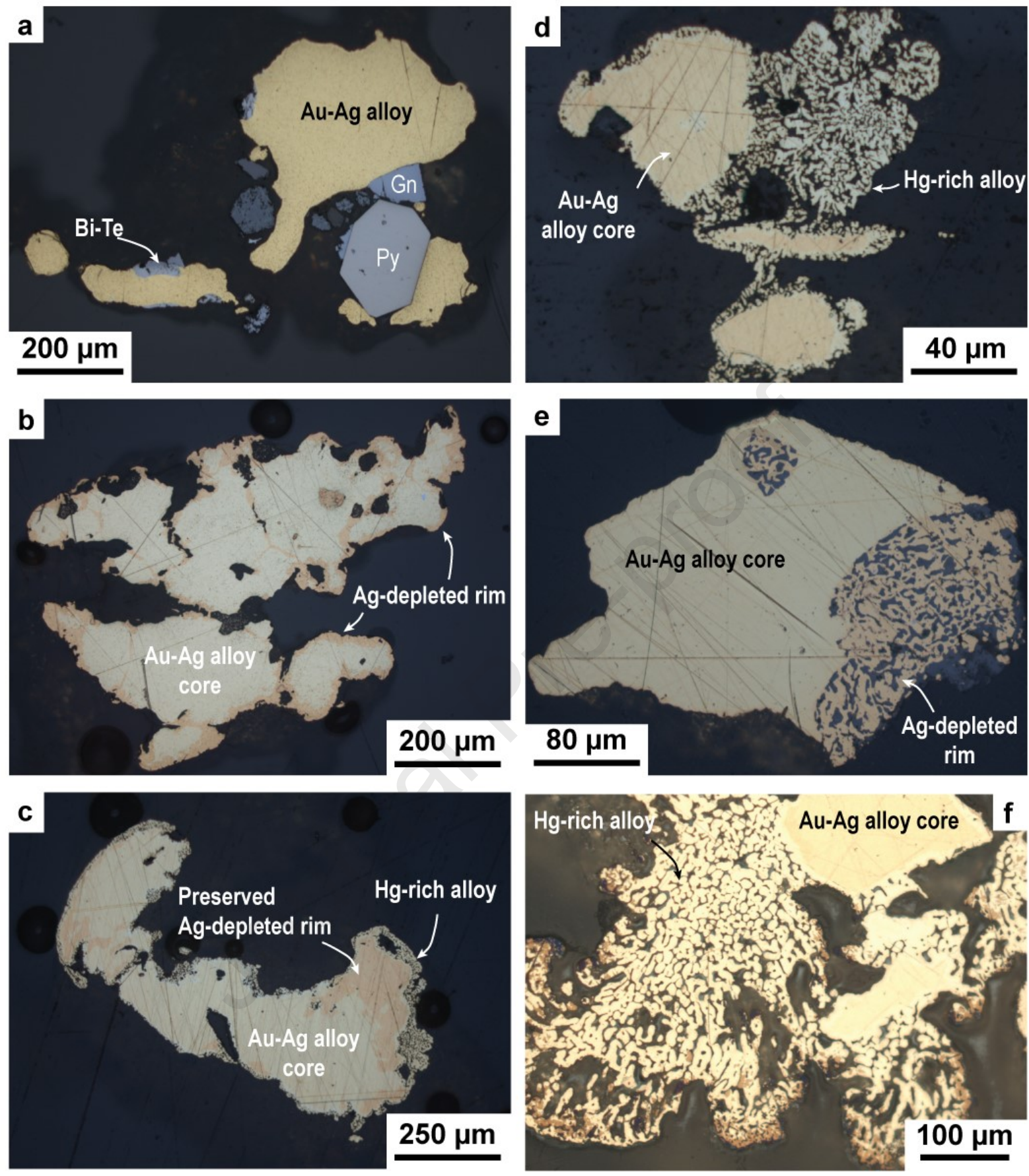

Fig. 3 Reflected light optical microscope images of different types of gold grains from French Guiana and Suriname. (a)

Primary gold grain with irregular outline composed of angular edges, embayments and classic primary mineral inclusions of

galena (Gn), pyrite (Py) and bismuth telluride (BiTe). (b) Alluvial gold grain with typical Ag-depleted rim around Au-Ag

core. The rim is secondary, probably the result of self-electrorefining or dissolution-precipitation processes (Groen et al.

371 1990). (c and d) Hg-amalgamated gold grains displaying classical spongy crown texture. The Hg-rich alloy coats the 
373

374

375

376

377

378

379

380

381

382

383

384

385

386

387

a "brain-like" texture, commonly thought to be the product of a natural electrolytic mechanism that purifies the gold. (f) Hgamalgamated gold grains displaying classic spongy crown texture (Benzdorp area, Suriname)

\subsubsection{A novel spectroscopic method to detect mercury}

To track illegally mined gold grains in the field, a fast and easy method is needed to measure the presence of $\mathrm{Hg}$ at the surface of raw gold grains (i.e. no sample preparation), compared to optical microscopy characterization which requires polishing. The use of a novel technique such as the handheld LIBS is promising because the focused laser beam $(50 \mu \mathrm{m})$ is narrow enough to take measurements on small gold grains. For this study, the emission line at $546.08 \mathrm{~nm}$ was selected for $\mathrm{Hg}$ (among other possibilities) because it is the most intense. As expected, LIBS analyses of raw gold grains from the group D did not detect $\mathrm{Hg}$ at the surface of the gold grains (Fig. 4a). This gold population comes from a legal mining operator who extracted the gold by conventional gravity techniques. On the other hand, LIBS analyses on samples from a Suriname (i.e. extracted with $\mathrm{Hg}$ amalgamation) show a strong peak at $546.08 \mathrm{~nm}$ (Fig. 4b), indicating the presence of $\mathrm{Hg}$ at the surface of the raw gold grains. When the mean spectra of each population are plotted together (Fig. 4c), the relative difference in the amplitudes of the peak intensities is large enough to confidently distinguish populations of gold grains extracted with mercury from those extracted without. Even when the cores of polished gold grains were analyzed (Fig. 4d), the peak at $546.08 \mathrm{~nm}$ was still significantly higher, meaning that $\mathrm{Hg}$ used during the amalgamation process can even be detected in the grain core. It is also important to note that the presence of $\mathrm{Hg}$ is not uncommon within natural gold (Von Gehlen, 1986; MacKenzie and Craw, 2005; Chapman and Mortensen, 2016; Chapman et al., 2000a, 2010a, 2010b, 2017), in the orogenic gold as well as in the alluvial gold. However, $\mathrm{Hg}$ is relatively homogenously distributed in the core (Von Gehlen, 1986; MacKenzie and Craw, 2005), compared to amalgam where $\mathrm{Hg}$ is mainly localized in the rim and heterogeneously distributed. Indeed, even though $\mathrm{Hg}$ can be detected in some grains from the group N (Fig. 4e), a naturally Hg-rich gold population (Appendix A.1), the mean intensity of the spectral line of interest $(546.08 \mathrm{~nm})$ is half that of the Suriname samples. Finally, the 258 analyses from the other gold populations of French Guiana, extracted without $\mathrm{Hg}$, do not display a peak at $546.08 \mathrm{~nm}$ (Fig. 4f), making the LIBS technique both dependable and useful for this application. 

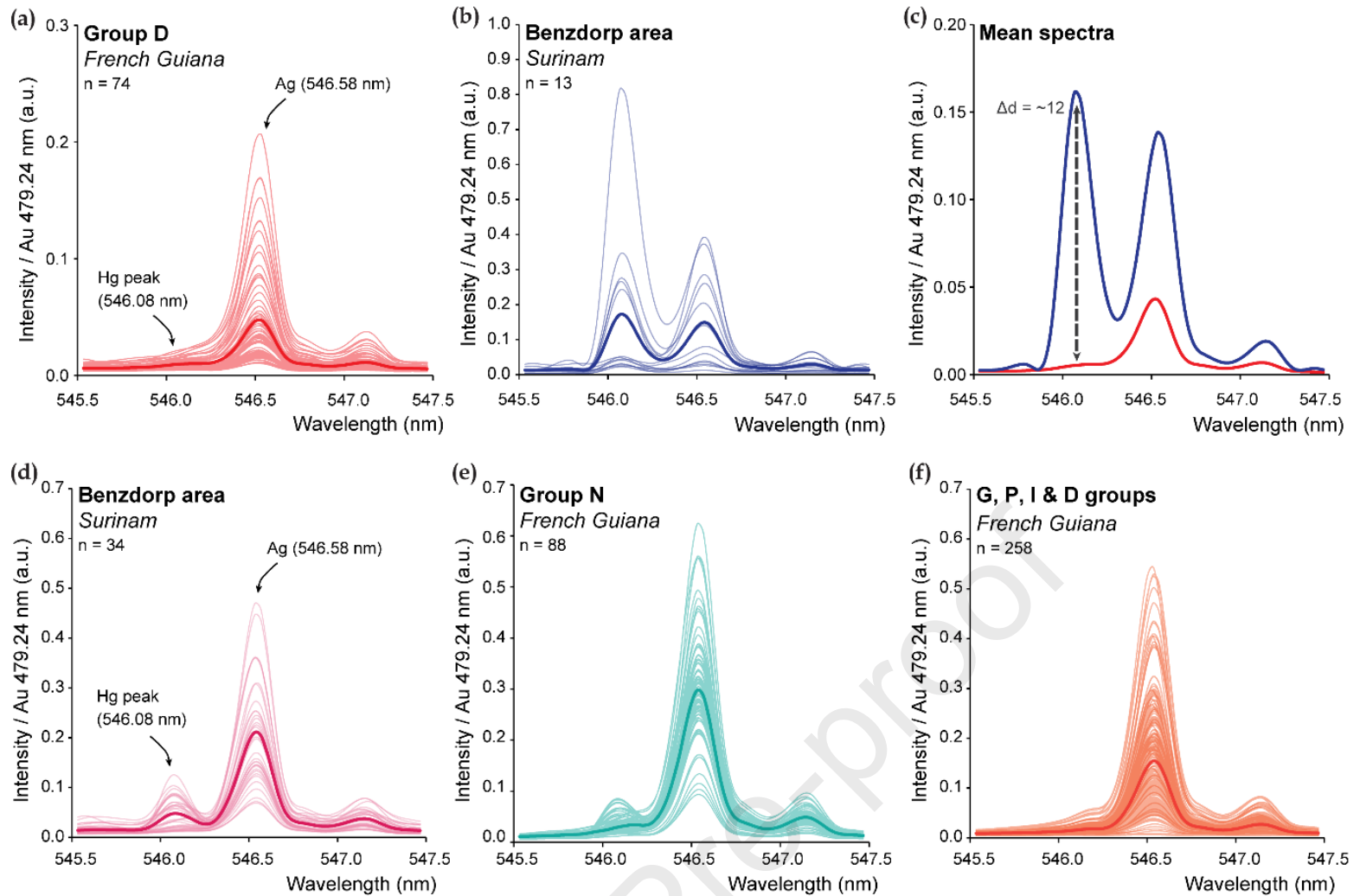

Fig. 4 Laser induced-breakdown spectra of raw (a-c) and polished (d-f) gold grains with a focus on $\mathrm{Hg}$ and $\mathrm{Ag}$ emission lines (i.e. between 545.5 and $547.5 \mathrm{~nm}$ ). (a and b) LIBS spectra for natural raw gold from the group D (French Guiana) and amalgamated gold from Benzdorp (Suriname). (c) The mean spectra of the two gold populations are displayed on the same plot to show the relative difference in the amplitude of peak Hg intensity. LIBS spectra of polished gold coming from the Benzdorp area (d), the naturally Hg-enriched group N (French Guiana) (e), and G, P, I and D groups (f). Bold lines correspond to the mean values of each gold population.

\subsection{A methodological approach to the certification of responsible gold supply chains}

In this study, the method used for gold traceability particularly focus on the Ag content because it is the only element (with gold) systematically present in any gold alloy and homogeneous within the grain core. Moreover, the CDF of the Ag content, when coupled with the KS statistic, greatly helps to discriminate distinct populations of gold grains and thus trace gold grain provenance (Pochon et al., 2020). In this study, Ag content was measured by EPMA. A similar approach using handheld LIBS on "polished" gold grains was deemed practical (Pochon et al., 2020), as was an SEM-EDS (Velazquez, 2014). 

Chapman, 2019) by resampling several aliquots at a given location but at different time (sometimes several years later). The obtained CDFs of the Ag content of these gold samples yield similar pattern, highlighting that (1) a gold sample can be considered as a representative aliquot of a population and (2) that results are reproducible. Thus, our dataset (i.e. similarly sampled) can be considered as representative aliquots of each studied gold population. In addition, we have also verified from what sample size our data are reproducible by performing a statistical procedure of random resampling of our dataset and compare it. Indeed, the comparison of subsamples obtained by the resampling allow the evaluation of the reproducibility of the sample distribution. The entire group $\mathrm{N}$ has been chosen to evaluate the sample size required (i.e. the number of gold grains needed by sample) to obtain accurate and reproducible results, because it contains the most gold grains analyzed (i.e. 165 analyses) and a large range of $\mathrm{Ag}$ contents (0.13 and 19.05 wt. \%). We thus randomly sampled without replacement fifty samples with different sample size: 5, 10, 15, 20 and 25 analyses. All possible KSD of two-sample comparisons were computed (i.e. 1225 combinations for each different sample size) and displayed in Fig. 5a. Because the D critical is dependent on the sample size, we evaluated the rate of false negative response with the specific-deposit DC from the KS17 approach. Unsurprisingly, resampling shows that the reproducibility is dependent on the sample size. Indeed, a low number of analyses tend to increase the KSD between samples coming from the same provenance and consequently leads to an increase of false negative response $(35.1 \%$ and $26.4 \%$ for a sample size of 5 and 10, respectively). Although the more analyses we have the better the result, it appears that data are reproducible from a sample size of 15 analyses (see 50R15, Fig. 5a), because the number of false negative response drastically decrease to only $6.7 \%$ (4.2\% for a sample size of 20$)$. With a mean sample size higher than 15 , our dataset can be considered as representative aliquot of a given population. Because the major part of our dataset consists of alluvial gold coming from placer, the primary source of gold grains can be multiple. We thus have assessed the ability of the KSD approach to identify samples coming from a placer composed of distinct contributing primary populations. To do so, we randomly generated a placer from three primary gold populations (i.e. A, C and T groups) and randomly sampled without replacement ten samples with a sample size of 15 (Fig. $5 b)$. Results show that all randomly selected samples well fit with the placer, meaning that the number of contributing primary sources has no effect on our method and in the studied Ag content range. 
(a)

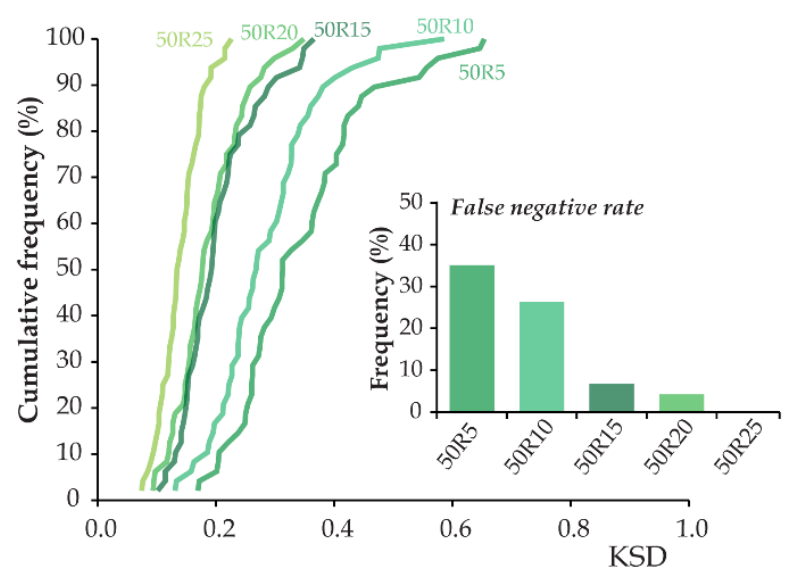

(b)

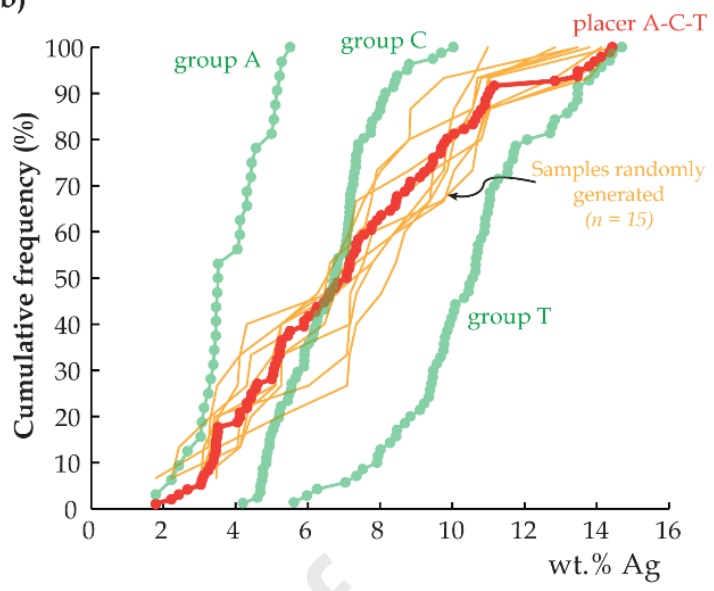

Fig 5 (a) Cumulative distribution functions of the Kolmogorov-Smirnov statistic (KSD) applied to the Ag content for all possible two-sample comparisons. 50R5 means that 50 samples of 5 analyses have been randomly sampled, and so on. (b) Cumulative distribution functions of the Ag content of randomly generated placer and randomly selected samples.

For successful application of our approach in gold traceability, it is essential that two samples from the same location must be identified as brother samples coming from the same gold population. At the opposite, two samples coming from different place must be identified as non-brother samples. The "classical" KS test and the KS17 approach were applied to dataset. Thus, all possible comparisons between brother samples have been evaluated together. The same was done with non-brother samples. For evaluating the "classical" KS test, 92 twosample comparisons of brother samples and 1148 two-sample comparisons of non-brother samples were possible. Results are plotted in Fig. 6a. KSD is normalized to the D critical and $\log 10$-transformed for a straightforward comparison between two samples. If the value is less than 0 , the two samples are considered as brother samples. Thus, we can see that curve of brother samples fall into the brother field (see green field in Fig. 6a) with only $2.2 \%$ of FN rate (for false negative rate), whereas the larger part of non-brother curve fall into the non-brother field (see orange field in Fig. 6a) with a FP rate of $28.9 \%$ (for false positive rate). Regarding the KS17 approach, a greater number of comparison were possible (134 two-sample comparisons of brother samples and 2193 two-sample comparisons of non-brother samples). The number of pair-wise comparisons is higher in the KS17 approach, because the "classical" KS test does not take into account permutations. Indeed, the pairwise comparison N2 vs N3 and N3 vs N2 would yield a distinct result in the KS17 approach, because the establishment of the decision criterion (DC) is based on a leave-one-out method that change with permutations, whereas the D critical is only based on the sample size (which remains unchanged when we permuted data). 
Results of KS17 approach are different when using standard or deposit-specific DC as decision criterion (Fig. 6b). Brother curves mainly fall into the brother field with a FN rate of $10.4 \%$ for the standard DC and a null FN rate for the deposit-specific DC. The major part of non-brother curves fall into the non-brother field with a FP rates of 32.6-35.0 \% for the deposit-specific and standard DC, respectively. Both approaches using KS statistic yielded very low FN rates results (i.e. $0-10.4 \%$ ) which is suitable and expected in traceability purposes. Using a deposit-specific DC seems to reduce the FN and FP rates (Gäbler et al., 2020). provenance. The use of deposit-specific DC from the KS17 approach is more appropriate for traceability when there is sufficient reference samples (i.e. at least 5 reference samples for one mine site), but the "classical" KS test should be used instead of the standard DC when there is not sufficient data. For this reason, we used the "classical" KS test in the remainder of this study.

479

(a) "classical" KS test

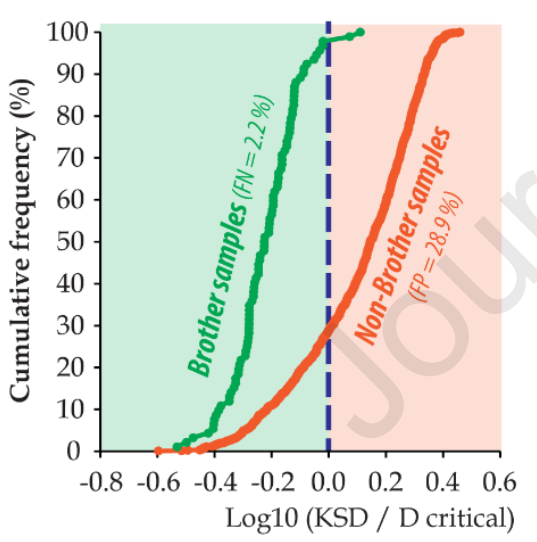

(b) the KS17 approach

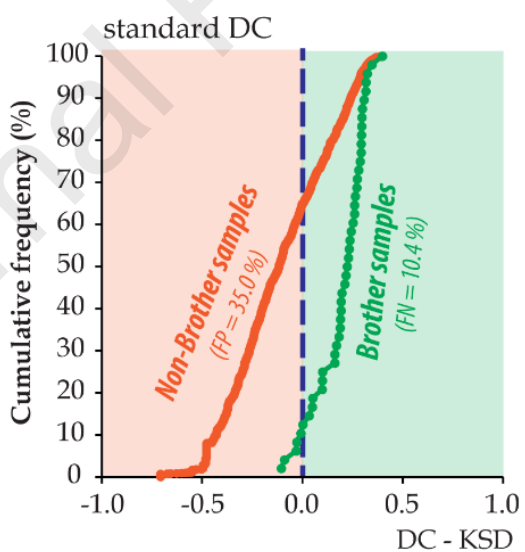

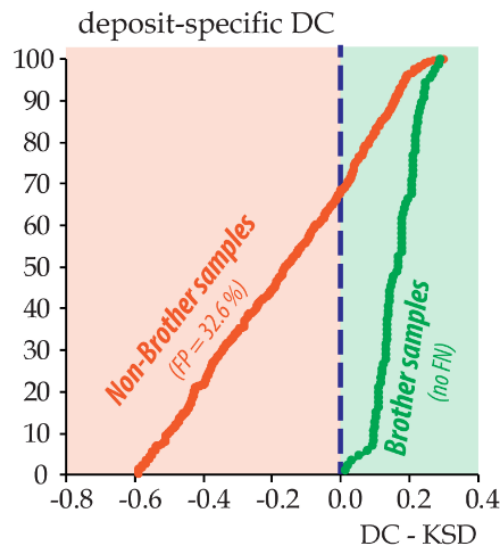

Fig. 6 Cumulative distribution functions of the KSD applied to the Ag content for brother and non-brother samples coupled to the decision-making criterion related to (a) the "classical" KS test and (b) the KS17 approach from Gäbler et al. (2017). FN and FP stand for the proportion of false negative and positive response, respectively. See text for further explanations.

To illustrate our approach within traceability process control, we have displayed two characteristic examples in the Fig. 7. Primary and alluvial gold grain populations are compared separately because their morphological characteristics are distinct and therefore constitute two different types of gold (i.e. a gold sample declared as being primary cannot be alluvial). The color code from the Fig. 7 follows the same reasoning than 
that of the Fig. 6. The green represent the brother field whereas the orange represent the non-brother field. It means that if the result of a brother comparison falls into the orange field, there is a FN response, and inversely. When the sample in question have a documented origin, results show that the two gold samples (i.e. samples A1 and P5) can be statistically identified to their gold population using their Ag contents. Indeed, the $\log 10$ (KSD/D critical) value obtained (green bar) from the comparison between the sample A1 and the group A fall into the brother field (green field), meaning that the declared origin of sample A1 as belonging to group A is correct (Fig. 7a). Moreover, the cumulative distribution curve of sample A1 fits perfectly with that of the group A. Same reasoning can be applied to the sample P5 (Fig. 7b). The declared origin of sample P5 as belonging to group P is correct. However, when we do not have documented origin, the sample P5 could be also belong to the group F, and therefore requiring further study to identify its unique provenance. Not surprisingly, this type of case is frequent and will become even more so as the number of studied gold occurrences increases, although other analytical tools can be used to improve the discrimination (see the following section). Nevertheless, Ag content is still considered the cornerstone of gold traceability studies because the process is efficient, and the parameter is sufficiently accurate to certify the declared gold population provenance in "routine" traceability studies. Even if Ag contents and KS statistic alone cannot distinguish all gold grain populations, they do help identify gold grain origin by reducing the number of possibilities, making this step the most decisive in our approach to the analytical traceability of natural gold. 


\section{(a) Primary gold}

sample "A1" ( $n=21)$
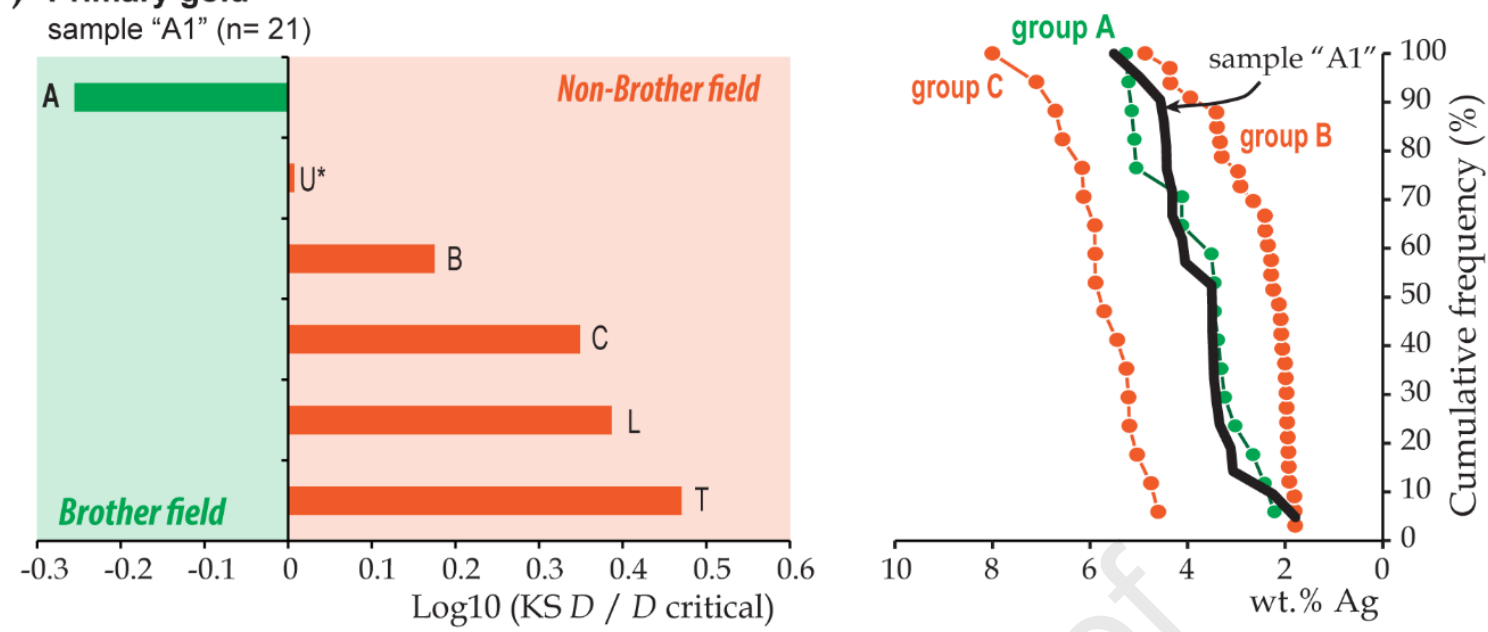

(b) Alluvial gold

sample "P5" $(n=21)$
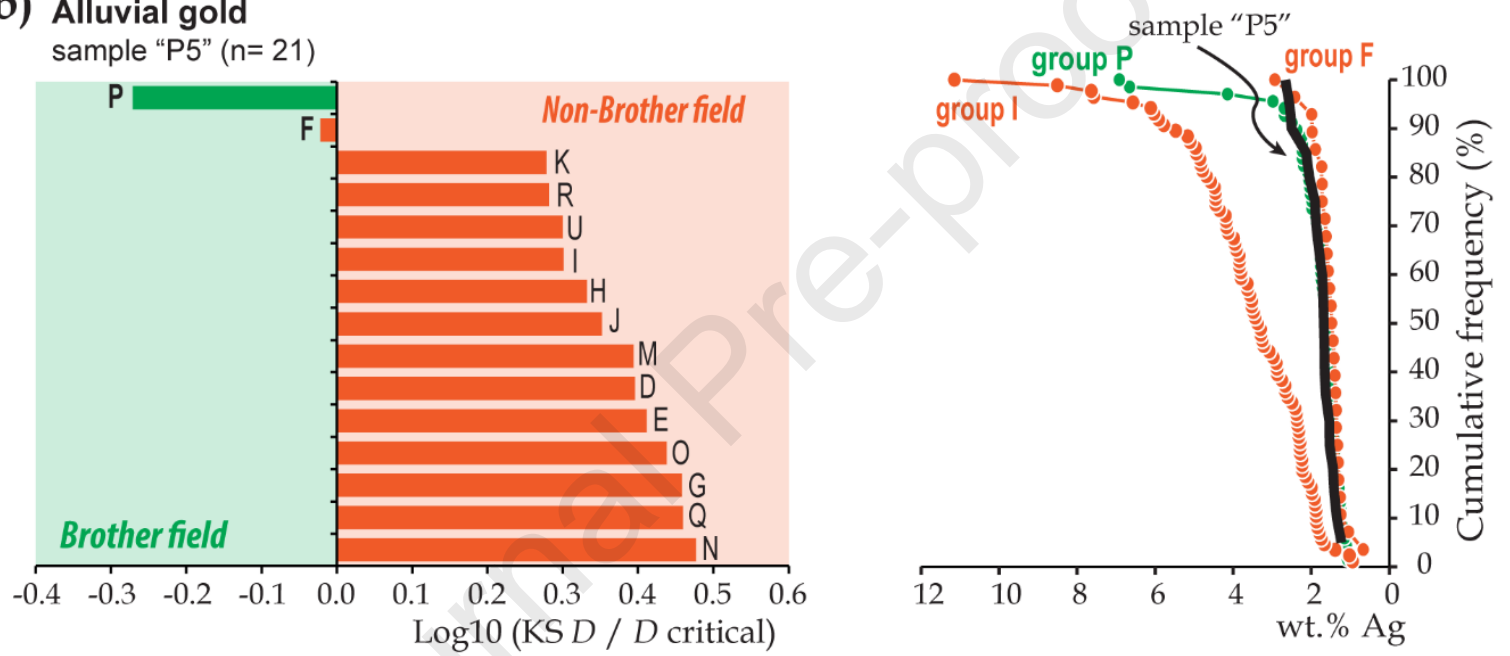

Fig. 7 Bar chart of the KS statistic (coupled with the decision-making criterion, D critical) and cumulative distribution curves of the Ag content of primary gold (a) and alluvial gold (b) samples illustrating our approach for verifying gold grain declared origin. Each sample was compared to all the studied gold populations, simulating a known database to which we could refer. Group A only refers to sample A2 in this case study, as there are only two subsamples that make up group A. The gold population of group P is composed of subsamples P1, P2, P3 and P4. The group $\mathrm{U}^{*}$ is composed of only one sample (U4). This sample is primary gold and comes from the same location of alluvial gold samples U1, U2 and U3. For this reason, they are treated separately. "n" correspond to number of electron microprobe analyses.

Adopting such an approach requires guidelines for implementation, knowledge about the presumed provenance of the sample, and a reference database. For practical implementation, the number of gold grains required (and consequently, the number of chemical analyses) appears critical to the traceability process because under-sampling may yield more false positives and some false negatives, leading to misinterpretation. Looking 
at our dataset and the random resampling (Fig. 5), we showed that a sample give reproducible data from 15 analyzed gold grains, but it is clear that the more we have the better. For a relevant database, it appears important to have reference samples coming from the same location with common origin (brother samples), and reference samples of different origins that do not share a common origin (non-brother samples). Ideally, at least five reference samples from the same location should be compiled for the calculation of the deposit-specific decisionmaking criterion, a well-tried approach. A database could not encompass all gold deposits around the world but rather must be established at a country or regional scale. If a traceability process is implemented, the database will continue to grow as new extraction sites open, and the number of gold populations with similar characteristics should also grow. In French Guiana, most of gold mining licence lasts for a maximum of 4 years and can be renewed only once. Extraction sites are thus not all active at the same time, which will reduce the number of similar gold populations extracted during the same period. This information should be available in the database, which must be updated regularly by the competent authorities. In addition, providing time information and deposit-specific location information can be useful in the case of deposits where composition evolves horizontally and/or vertically.

This analytical approach may help control and certify gold production and trade. Such as several published papers (Gäbler et al., 2013, 2017, 2020; Martyna et al., 2018), we consider a gold sample that matches its presumed provenance to be certified gold even if it matches other referenced gold samples from the database, but we believe it should be evaluated and validated on a case by case basis in accordance with current legislation. Since it is difficult to predict the Ag distribution in a "raw" gold sample without polishing and chemical analysis, it would be useless to attempt to imitate a particular signature, because it needs time to do this; a time that illegal miners do not have. The systematic use of $\mathrm{Hg}$ amalgamation by illegal miners can be easily detected by the use of handheld LIBS directly in the field or in a mobile field laboratory. In addition, certifying responsible gold supply chains directly in the field could be possible. Pochon et al. (2020) have demonstrated that a handheld LIBS may be also used as an EPMA substitute for determining Ag content in gold. In this case, manual rough polishing of raw gold grains would expose the core of the grain, thereby reducing the cost and sample preparation time, and the process could be done in a field laboratory. Our analytical approach is thus achievable in the field and in a field laboratory, allowing for easier implementation of the due diligence process, certification of the origin of the gold and demonstration of responsible sourcing. 


\subsection{Identifying the origin of unknown gold samples: a challenging issue}

551

552

553

554

555

556

557

558

559

560

561

562

563

564

565

566

567

568

569

570

571

572

573

574

575

576

577

578

In addition to the implementation traceability process for natural gold, it needs complementary tools to help identify the provenance of gold diverted from a legal supply chain and illegal gold seized by authorities. This would serve to locate the rightful owner or to locate the area devastated by illegal mining and stop the illicit extraction. However, when a greater precision is needed, the analytical methods become more expensive and time-consuming. The use of minor elements (especially $\mathrm{Cu}$ and $\mathrm{Hg}$ ), the identification of mineral inclusions, and the quantification of trace element fingerprints may help to discriminate gold populations within some specific case.

\subsubsection{Input of minor elements}

Although the detection limits of a traditional analytical method such as EPMA are often too high to detect $\mathrm{Cu}$ and $\mathrm{Hg}$ in every gold grain (Fig. 8a), it is a very useful tool because it allows the number of variables to be increased. Although the group $\mathrm{N}$ is similar to the $\mathrm{Q}, \mathrm{M}, \mathrm{E}$ and $\mathrm{G}$ groups in terms of $\mathrm{Ag}$ content distribution (Appendix A.1), the gold from the group $\mathrm{N}$ can be easily identified by its $\mathrm{Hg}$ content. For example, sample $\mathrm{N} 4$ has a mean value of $0.38 \mathrm{wt} \% \mathrm{Hg}$ with $26 \%$ of the gold grains containing a significant amount of $\mathrm{Hg}$, whereas the $\mathrm{Hg}$ concentrations in the gold from the Q, M, E and G groups are generally below the detection limit (i.e. $0.28 \mathrm{wt} \%)$. The $\mathrm{Hg}$ content for sample $\mathrm{N} 4$ is specific to the gold from the group $\mathrm{N}$, which also has a mean value of $0.31 \mathrm{wt} \% \mathrm{Hg}$, with mercury detected in $26 \%$ of the EPMA analyses. The group $\mathrm{N}$ is the only example of natural Hg-bearing gold known to date in French Guiana with a range composition close to amalgams from Suriname (Fig. 8a), making its identification relatively easy, but it may be not so easily in areas where $\mathrm{Hg}$ is a common. Indeed, only $3.8 \%$ of our data contains significant $\mathrm{Hg}$ content meaning that French Guiana gold is relatively Hg-poor compared to others goldfields (e.g. Von Gehlen, 1983; Chapman, et al., 2000a, 2010a, 2010b, 2017; MacKenzie and Craw, 2005; Chapman and Mortensen, 2016). The same reasoning can be applied to the gold from the group $\mathrm{M}$ based on its significant $\mathrm{Cu}$ content (up to 8.3 wt.\% Cu, Fig. 8b), detected by EPMA, compared to the other populations (i.e. a mean value of $0.26 \mathrm{wt} \% \mathrm{Cu}$ with $17 \%$ of gold grains containing significant $\mathrm{Cu}$ ), thereby allowing for rapid identification of the gold from group M. Such as the $\mathrm{Hg}$ content, the $\mathrm{Cu}$ content is not always detected by EPMA (only $21.2 \%$ of our data contains significant $\mathrm{Cu}$ content, Fig. $8 \mathrm{~b}$ ), making difficult the systematic use of these two elements in traceability method. 
(a)

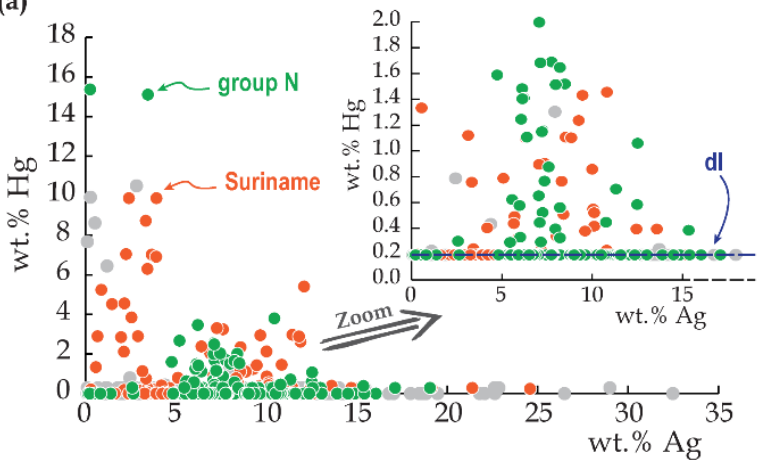

(b)

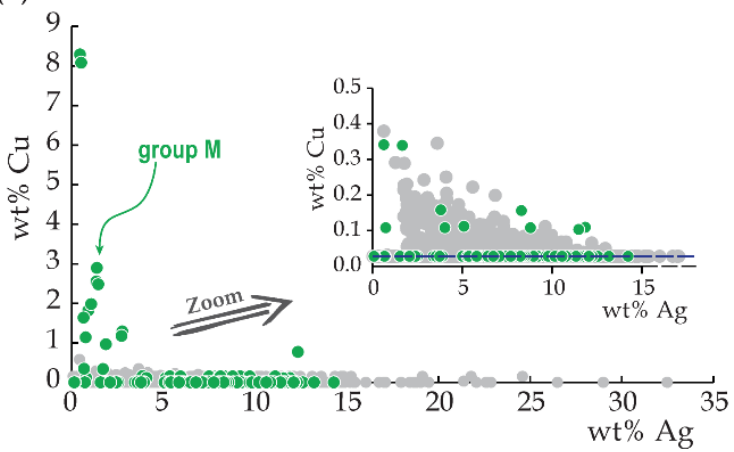

Fig. 8 Binary plots showing the $\mathrm{Ag}$ content versus the $\mathrm{Hg}$ content (a) and the $\mathrm{Cu}$ content (b) of gold from this study. Grey dots consists of others French Guiana gold and "dl” stand for detection limit.

\subsubsection{Contributions from mineral inclusions, a source of powerful but fragmentary data}

Studies on mineral inclusion assemblages to discriminate different gold populations have been performed since the 1970s (Desborough et al., 1971), and it is now considered a traditional approach to identifying different styles of mineralizing events and a mineral exploration tool for tracking down primary deposits (Chapman et al., 2000b). Indeed, the formation of mineral inclusions within native gold is generally interpreted as sub-coeval and provides information about the environment of formation (Chapman et al., 2000b). Furthermore, the mineral inclusions located in the core of gold grains are preserved by gold's ability to form an effective natural barrier between inclusions and the atmosphere (Chapman et al., 2002). However, to develop a robust interpretation based on mineral inclusion data, a large number of gold grains must be collected (i.e. about 150 particles for Chapman et al. (2021)) and characterized because most are devoid of such inclusions (e.g. only 5\% of gold grains host inclusions in the Klondike Gold District; Chapman et al., 2010a). Thus, all gold grains must be carefully examined in order to identify the presence (or absence) and type of inclusions. Unsurprisingly, only a few gold grains (less than 17\%) host mineral inclusions, providing incomplete information on inclusion mineralogy, thereby making robust statistical analyses more challenging. In some cases, when the information on Ag content distribution is insufficient, it is possible to use the mineral inclusion information to identify the provenance of a gold sample. For example, sample T4 (when considered as an unknown) could belong to either the $\mathrm{L}$ or $\mathrm{T}$ groups based on its Ag content (Fig. 9a and b), but the absence of maldonite inclusions (AuBi) shows that it belongs to the T gold population because maldonite was only found in samples from the group L (Fig. 9c). But it is important to keep in mind that the absence of such mineral inclusions may also be due to fluvial transport that may partly obliterated inclusions information (Melchiorre and Henderson, 2019) yielding 
incomplete data. In addition, all the samples from the group P (i.e. 9, 30, 38, 46 and 47) have similar Ag contents

604 to the group F, but the mineral inclusion assemblages highlight the differences between them (Appendix A.3).

605 Mineral inclusions in gold from the group F are mainly galena ( $\sim 6 \%)$ whereas inclusions from the group P are galena ( 55\%), Bi telluride ( 18\%) and Pb telluride ( 8\%). Thus, sample P5, which could belong to either the $\mathrm{P}$ or F gold populations (Fig. 6b), is easily identified as a brother sample of the group P using mineral inclusion information. Thereby, mineral inclusions can be very useful to help match samples to gold populations when the gold grains host sufficient and characteristics mineral inclusions. However, it is not suitable for "routine" analyses in traceability purposes because it needs quick decision making that is not possible if at least 150 gold particles are required. This method should be only used to dig deeper into discrimination when required, and consequently should be used in complement to the KS statistic applied to the Ag content. 
(a)

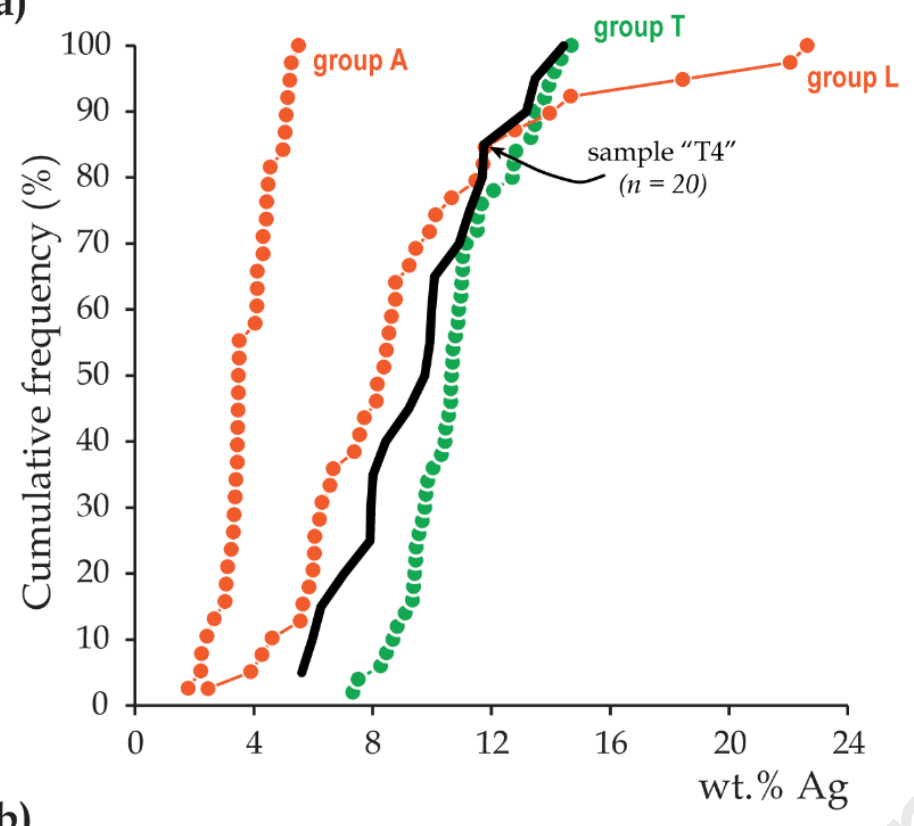

(b)

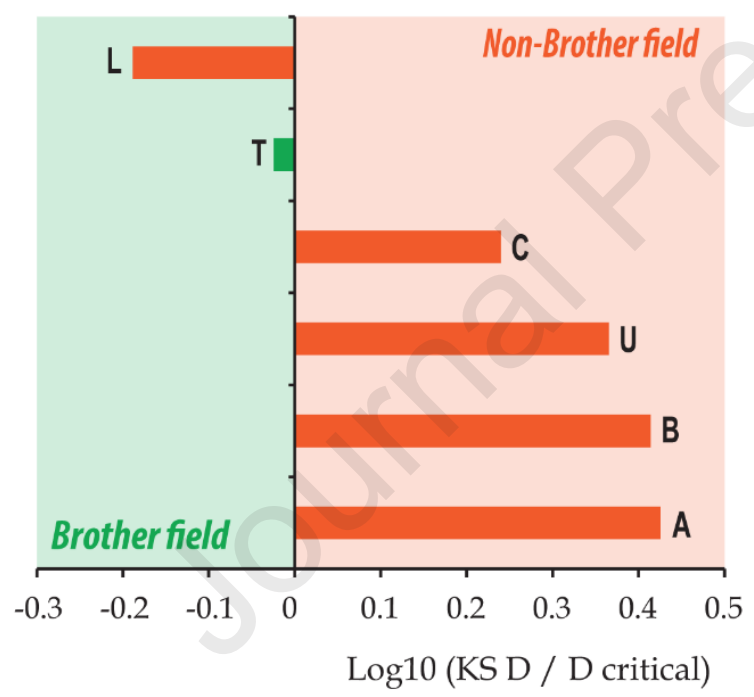

(c)

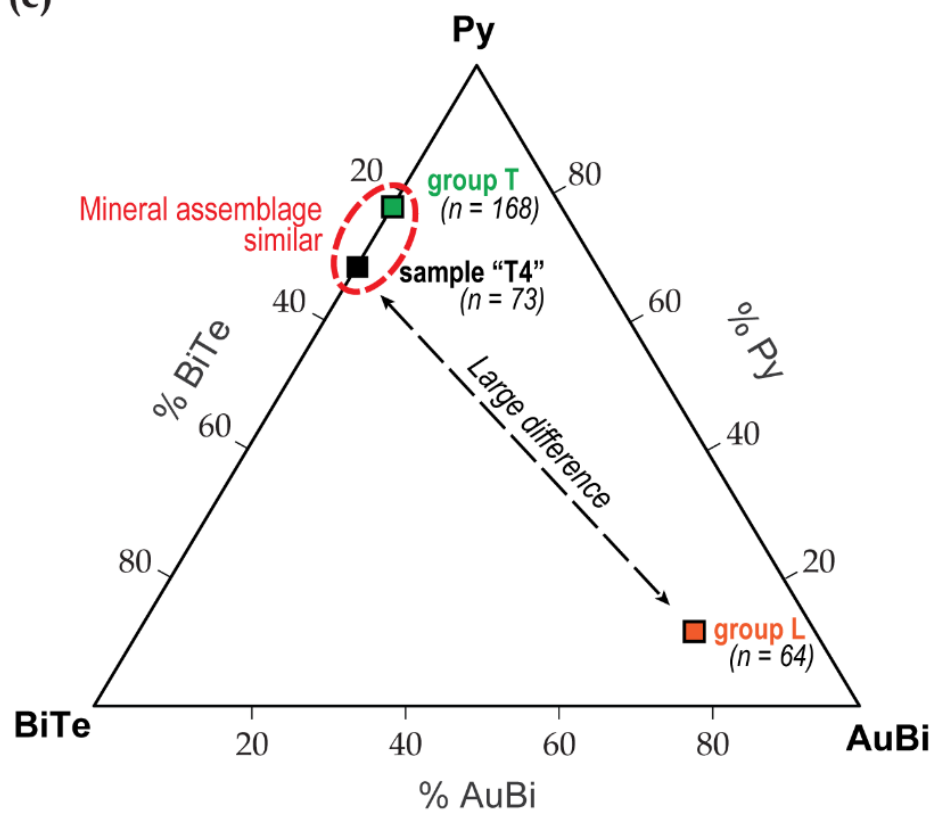


Fig. 9 Cumulative distribution plot of the Ag content of primary gold (a). Bar chart of the KS statistic coupled with the D critical (b). Ternary plot of the statistical counting data on mineral inclusions in sample $\mathrm{T} 4$ and gold grains from the $\mathrm{T}$ and $\mathrm{L}$ gold populations (c).

\subsubsection{Trace element fingerprinting}

Deciphering gold fingerprints using trace elements is increasingly used in ore deposit studies (Banks et al., 2018; Chapman et al., 2021; Liu and Beaudoin, 2021; Liu et al., 2021) and is the most common technique for identifying the source of illicit gold (Watling et al. 1994, 2014; Dixon and Merkle, 2019). However, in previous traceability studies this technique is only applied to raw spectral data without any calibration or standardization with matrix-matched reference materials. In addition, the comparison between different gold populations is mainly based on trace element patterns and rarely coupled with multivariate statistical analyses. Thus, we propose here an approach using PERMANOVA and SIMPER analyses on trace element compositions as determined by LA-ICP-MS to identify gold provenance. The former was used to test the dissimilarity between gold populations, whereas the latter highlights the trace elements that contribute to the dissimilarity. This approach was performed on gold samples that could not be matched to a unique provenance using other analytical methods (Appendices A.4, A.5 and A.6).

Sample I4 from the group I is shown as an example of this method in Fig. 10. When treated as an unknown, the KSD approach on the Ag content (Fig. 10a) identify four possible brothers population for the sample I4 (I, K, R or U groups). PERMANOVA analyses compared the trace element composition of sample I4 to samples from each of the four possible populations. Only five trace elements $(\mathrm{Cu}, \mathrm{Pd}, \mathrm{Cd}, \mathrm{Sb}, \mathrm{Bi})$, analyzed by LA-ICP-MS, were used (other trace elements were not suitable as they were principally below the limit of detection). The SIMPER results showed that the average dissimilarity for each trace element varies significantly from one gold population to another (Fig. 10b). When sample I4 is compared to the I and K populations, the contributing dissimilarity of $\mathrm{Pd}$ varies from 10.9 to 27.9 , respectively, making this element the most discriminative. The PERMANOVA results clearly show a statistically significant similarity in trace element composition for I4 compared to gold from the group I, yielding a pseudo-F ratio of -0.082 and a p-value of 0.9480. As for the other gold populations (Fig. 10b), the pseudo-F ratio values are significantly higher (from 6.8 to 12.1 ), and the p-values significantly lower than 0.05 (from 0.0001 to 0.0003 ). This test undoubtedly indicates that sample I4 belongs to the group I, successfully tracing its origin. 
644 of 12 other samples (Appendix A.5). Consequently, the origin of another 16 samples could not be certified due to

645 overly similar trace element fingerprints as evidenced by SIMPER results. They clearly show that most trace

646 elements almost equivalently contribute to the dissimilarity of these samples, explaining the challenge to

647 undoubtedly discriminate them. In conclusion, the provenance of $69 \%$ of the dataset (i.e. 39 of 56 gold samples)

648 could be correctly identified when the samples were treated as "unknowns", and the analytical process followed

649 a specific sequence of techniques (i.e. Ag content first, followed by minor element composition, then mineral

650 inclusion assemblage, and finally trace element composition). 
(a)

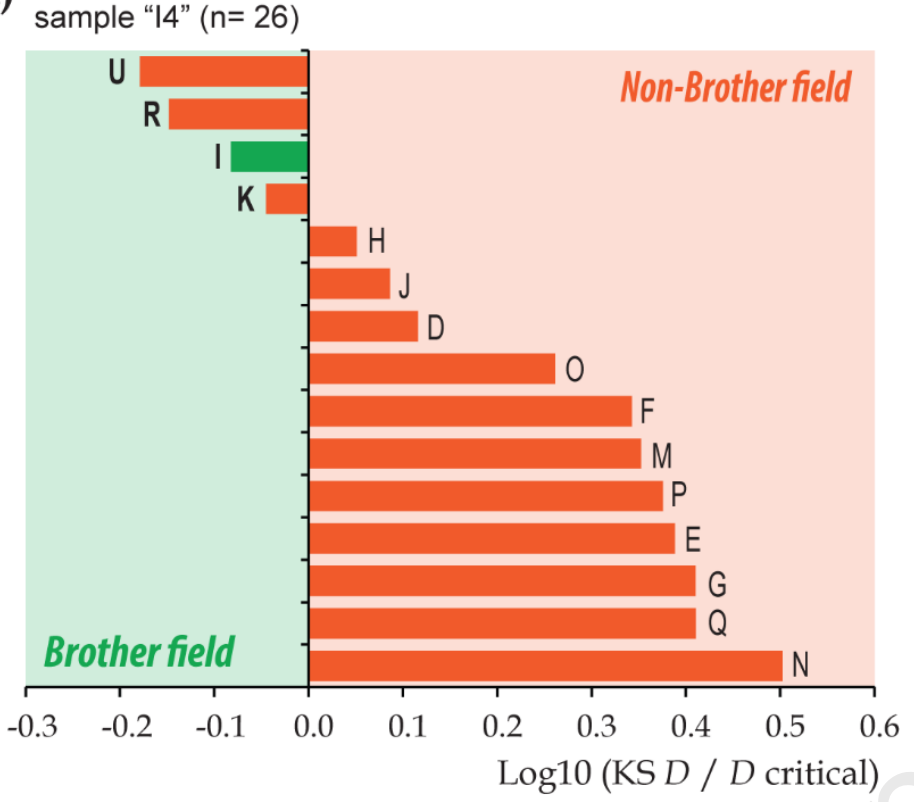

(b)

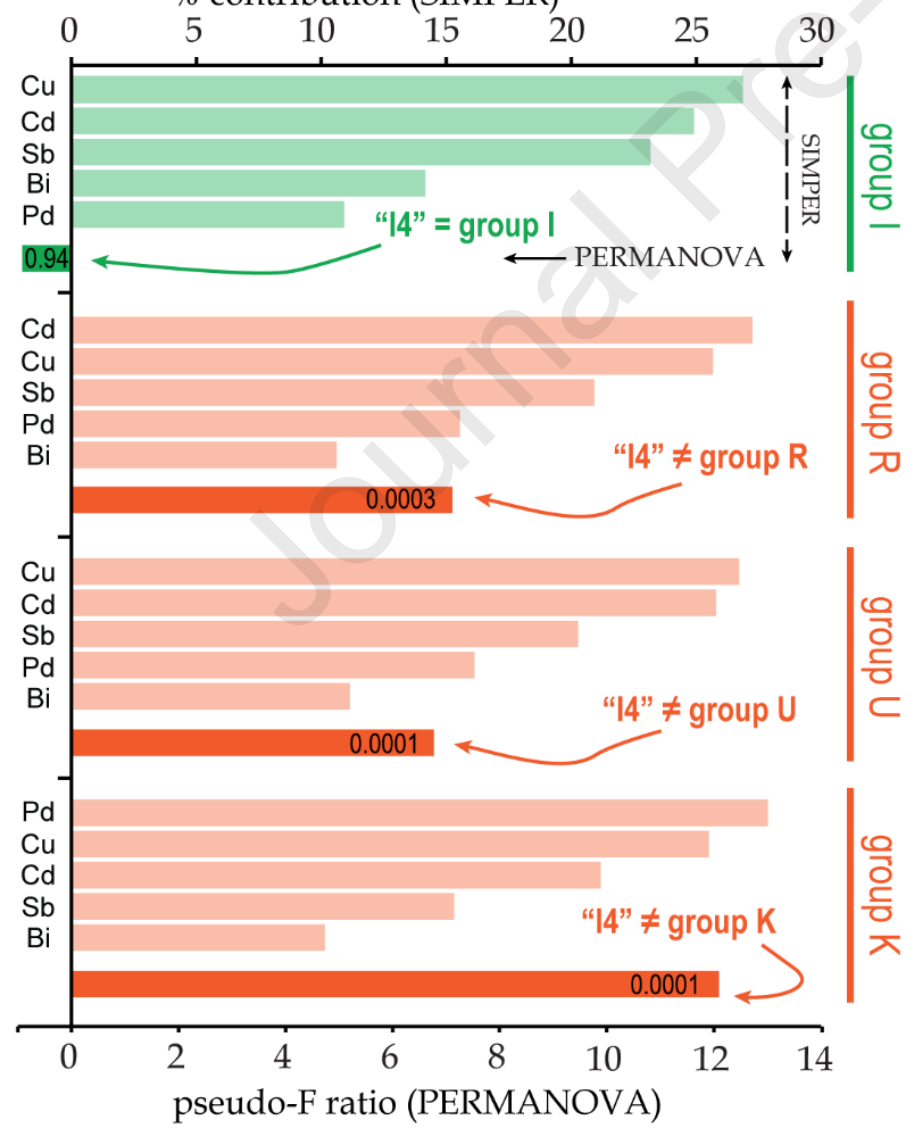

653 Fig. 10 Bar chart of the KS statistic coupled with the D critical performed on the Ag contents of sample I4 compared to other 654 gold populations (a). Results of the similarity percentage analysis (SIMPER) and the permutational multivariate analysis of 
variance (PERMANOVA) (b). The light colored bars represent the percentage contribution of each element to the dissimilarities (SIMPER). The dark colored bars represent the pseudo-F ratio (PERMANOVA), and the black values show

When gold samples were treated as unknowns, our approach could not correctly predict the provenance of 16 samples ( $\sim 31 \%$ of the dataset). This limitation mainly concerns samples from the $\mathrm{H}, \mathrm{J}, \mathrm{O}, \mathrm{R}$ and $\mathrm{U}$ gold populations. It becomes difficult to identify these samples and to link them to a unique extraction site when their origin is assumed to be unknown. Indeed, it is challenging to discriminate alluvial gold populations that share the same bedrock deposit contributing source (the interconnection of hydrographic networks and the geographical proximity between the $\mathrm{H}$ and $\mathrm{J}$ gold populations located only $13 \mathrm{~km}$ apart and between the $\mathrm{R}$ and $\mathrm{U}$ gold populations only $4 \mathrm{~km}$ apart support this assumption) or a bedrock deposit that share similar genetic processes (e.g. fluid composition, the nature of the host rocks and the source of the metals). Indeed, most gold deposits from French Guiana are hosted within the same Paleoproterozoic greenstone belt and are mostly overprinted by late orogenic gold event (Marcoux and Milési, 1993; Milési et al., 2003). Consequently, the gold extracted from placers derived from such primary deposits have similar geochemical signatures. Furthermore, in agreement with the recent study of Chapman et al. (2021), the trace element content of gold from orogenic environments, such as French Guiana gold, is relatively low. Only five elements (i.e. $\mathrm{Cu}, \mathrm{Pd}, \mathrm{Cd}, \mathrm{Sb}, \mathrm{Bi}$ ) are present in more than $60 \%$ of gold particles, making the multivariate statistic challenging. Using a femtosecond laser coupled with a highresolution ICP-MS could enhance the sensitivity of the trace element analysis by pushing down the detection limit of trace elements, which consequently may increase the number of detected trace elements and enhance the resulting multivariate statistical tests. But even the most advanced analytical methods will not resolve the uncertainty for samples with the same geological origin and related genetic processes. Keep in mind that seized gold is never entirely unknown and that determining its origin follows a forensic investigation that depends on the context of the seizure, the persons involved and the links to previous cases, and is therefore but one part of the information that helps trace the origin of the gold (Dixon and Merkle, 2019). Like the use of minor components or mineral inclusions, the trace elements fingerprint may help to go further into sample discrimination, but cannot substitute the KS method applied to the Ag content to trace and certify gold provenance within traceability framework. 
The main motivation of this study was to develop a multi-method approach to support and enhance the due diligence process of the traceability of gold. We have combined a range of geochemical and statistical methods in order to help confirm the provenance of legal gold samples and to remove illegal gold samples from the supply chain. Following three steps, our approach demonstrated that, in French Guiana, it is possible to identify illicit gold, to certify the provenance of natural gold, and if applicable, identify the origin of unknown gold. First step showed that the use of $\mathrm{Hg}$ amalgamation is easily discernible by the presence of spongy crown texture around gold grains (i.e. $100 \%$ of gold grains extracted by $\mathrm{Hg}$ amalgamation have such texture) and also by the detection of $\mathrm{Hg}$ in the field using a compact and lightweight spectroscopic method (LIBS). Indeed, all gold extracted by conventional gravity methods did not contain significant $\mathrm{Hg}$, except the $\mathrm{Hg}$-rich group $\mathrm{N}$ which is naturally enriched. The second and major step showed that the analysis of the distribution of Ag content coupled with a statistical KS approach are a powerful tool for certifying the gold provenance. Brother samples were mostly and correctly identified (i.e. only $2.2 \%$ of brother samples were misinterpreted with "classical" KS test) to their presumed provenance. The last and more challenging step (i.e. identifying the origin of unknown gold) requires multi-method approach. The use of the $\mathrm{Cu}$ and $\mathrm{Hg}$ content can be useful to distinguish gold population with peculiar signature. The determination of mineral inclusions is powerful to identify a gold population but the scarcity of such inclusions within gold populations needs large gold grain collection and makes its routine use complicated. LA-ICP-MS trace element composition, coupled with a permutational multivariate analysis of variance and a similarity percentage analysis, showed that trace element analyses can greatly help the identification of unknown gold as long as its source population is referenced in a database. However, it should be noted that too much similarity between some gold populations (i.e. $\sim 31 \%$ of the dataset) due to too close proximity or identical genetic processes cannot be resolved with the most advanced analytical methods. Application of our innovative multi-method approach in the French Guiana case study has demonstrated that this approach is relevant and works well. Keeping in mind that gold signatures may be locally more variable, now, the further challenges consist to enlarge the database and assess this approach in others regions across the world and to implement this approach to support the global supply chain of gold.

\section{Acknowledgments}


714

This work was supported by the CARNOT grant No. 17-CARN-003-01. Authors are grateful to Quantum RX who provided the Sci Aps Z-200 C+ instrument for analyzing the mercury in the gold grains. Bernard Gratuze and Georges Beaudoin are also thanked for providing us reference materials for the calibration of the LA-ICPMS analyses. Authors thank Guillaume Wille for EPMA analyses and Venetia Bodycomb for revising the earlier English draft. The manuscript was improved by review from Philippe Négrel. R. Chapman and an anonymous reviewer are greatly thanked for their valuable comments that largely improved the earlier version of the manuscript.

\section{References}

OECD Due Diligence Guidance for Responsible Supply Chains of Minerals from Conflict-Affected and HighRisk Areas, 2016. , OECD Due Diligence Guidance for Responsible Supply Chains of Minerals from Conflict-Affected and High-Risk Areas. OECD. https://doi.org/10.1787/9789264252479-en

Dodd-Frank Wall Street Reform and Consumer Protection Act, 2008.

Aitchison, J., 1982. The Statistical Analysis of Compositional Data. J. R. Stat. Soc. Ser. B 44, 139-160. https://doi.org/10.1111/j.2517-6161.1982.tb01195.x

Anderson, M.J., 2017. Permutational Multivariate Analysis of Variance (PERMANOVA), in: Wiley StatsRef: Statistics Reference Online. John Wiley \& Sons, Ltd, Chichester, UK, pp. 1-15. https://doi.org/10.1002/9781118445112.stat07841

Anderson, M.J., 2001. A new method for non-parametric multivariate analysis of variance. Austral Ecol. 26, 32 46. https://doi.org/10.1111/j.1442-9993.2001.01070.pp.x

Augé, T., Bailly, L., Bourbon, P., Guerrot, C., Viprey, L., Telouk, P., 2015. Faisabilité technique d'une traçabiltié physico-chimique de l'or de Guyane.

Bray, J.R., Curtis, J.T., 1957. An Ordination of the Upland Forest Communities of Southern Wisconsin. Ecol. Monogr. 27, 325-349. https://doi.org/10.2307/1942268

Banks, D.A., Chapman, R.J., Spence-Jones, C.P., 2018. Detrital gold as a deposit-specific indicator mineral by LAICP-MS analysis. Geoscience BC report 2018-21, Geoscience BC, Vancouver, 49 p.

Carisch, E., 2012. Conflict Gold to Criminal Gold : The new face of artisanal gold mining in Congo.

Chapman, R.J., Leake, R.C., Moles, N.R., 2000a. The use of microchemical analysis of alluvial gold grains inmineral exploration: Experiences in Britain and Ireland. J. Geochemical Explor. 71, 241-268. https://doi.org/10.1016/S0375-6742(00)00157-6 
Chapman, R.J., Leake, R.C., Moles, N.R., Earls, G., Cooper, C., Harrington, K., Berzins, R., 2000b. The Application of Microchemical Analysis of Alluvial Gold Grains to the Understanding of Complex Local and Regional Gold Mineralization: A Case Study in the Irish and Scottish Caledonides. Econ. Geol. 95, 1753-1774. https://doi.org/10.2113/gsecongeo.95.8.1753

Chapman, R.J., Mortensen, J.K., 2016. Characterization of Gold Mineralization in the Northern Cariboo Gold District, British Columbia, Canada, Through Integration of Compositional Studies of Lode and Detrital Gold with Historical Placer Production: A Template for Evaluation of Orogenic Gold D. Econ. Geol. 111, 1321-1345. https://doi.org/10.2113/econgeo.111.6.1321

Chapman, R.J., Mortensen, J.K., Crawford, E.C., Lebarge, W., 2010a. Microchemical studies of placer and lode gold in the Klondike district, Yukon, Canada: 1. evidence for a small, gold-rich, orogenic hydrothermal system in the Bonanza and Eldorado Creek area. Econ. Geol. 105, 1369-1392. https://doi.org/10.2113/econgeo.105.8.1369

Chapman, R.J., Mortensen, J.K., Crawford, E.C., Lebarge, W.P., 2010b. Microchemical studies of placer and lode gold in the Klondike district, Yukon, Canada: 2. Constraints on the nature and location of regional lode sources. Econ. Geol. 105, 1393-1410. https://doi.org/10.2113/econgeo.105.8.1393

Chapman, R.J., Leake, R.C., Warner, R.A., Cahill, M.C., Moles, N.R., Shell, C.A., Taylor, J.J., 2006. Microchemical characterisation of natural gold and artefact gold as a tool for provenancing prehistoric gold artefacts: A case study in Ireland. Appl. Geochemistry 21, 904-918. https://doi.org/10.1016/j.apgeochem.2006.01.007

Chapman, R., Mileham, T., Allan, M., Mortensen, J., 2017. A distinctive Pd-Hg signature in detrital gold derived from alkalic $\mathrm{Cu}-\mathrm{Au}$ porphyry systems. Ore Geol. Rev. 83, 84-102. https://doi.org/10.1016/j.oregeorev.2016.12.015

Chapman, R.J., Banks, D.A., Styles, M.T., Walshaw, R.D., Piazolo, S., Morgan, D.J., Grimshaw, M.R., SpenceJones, C.P., Matthews, T.J., Borovinskaya, O., 2021. Chemical and physical heterogeneity within native gold: implications for the design of gold particle studies. Miner. Deposita. https://doi.org/10.1007/s00126-020-01036-x

Chapman, R., Leake, B., Styles, M., 2002. Microchemical characterization of alluvial gold grains as an exploration tool. Gold Bull. 35, 53-65. https://doi.org/10.1007/BF03214838 
Clarke, K.R., 1993. Non-parametric multivariate analyses of changes in community structure. Aust. J. Ecol. 18, 117-143. https://doi.org/10.1111/j.1442-9993.1993.tb00438.x

Connors, B., Somers, A., Day, D., 2016. Application of Handheld Laser-Induced Breakdown Spectroscopy (LIBS) to Geochemical Analysis. Appl. Spectrosc. 70, 810-815. https://doi.org/10.1177/0003702816638247

Darlington, S., 2018. Illegal Mining, 'Worse Than at Any Other Time,' Threatens Amazon, Study Finds. The New York Times 12-14.

Decrée, S., Pourret, O., Baele, J.M., 2015. Rare earth element fractionation in heterogenite $(\mathrm{CoOOH})$ : Implication for cobalt oxidized ore in the Katanga Copperbelt (Democratic Republic of Congo). J. Geochemical Explor. 159, 290-301. https://doi.org/10.1016/j.gexplo.2015.10.005

Delor, C., Lahondère, D., Egal, E., Lafon, J-M., Cocherie, A., Guerrot, C., Rossi, P., Truffert, C., Théveniaut, H., Phillips, D., De Avelar, VG., 2003. Transamazonian crustal growth and reworking as revealed by the 1:500000 scale geological map of French Guiana. Géologie de la France 2-3-4:5-57

Desborough, G.A., Heidel, R.H., Raymond, W.H., Tripp, J., 1971. Primary distribution of silver and copper in native gold from six deposits in the Western United States. Miner. Depos. 6, 321-334. https://doi.org/10.1007/BF00201890

Desborough, G.A., 1970. Silver depletion indicated by microanalysis of gold from placer occurrences, western United States. Econ. Geol. 65, 304-311. https://doi.org/10.2113/gsecongeo.65.3.304

Dixon, R.D., Merkle, R.K.W., 2019. Identifying the source of illicit gold from South America. Geol. Soc. London, Spec. Publ. 492, SP492-2018-15. https://doi.org/10.1144/sp492-2018-15

Enjolvy, R., 2008. Processus d'accrétion crustale et régimes thermiques dans le bouclier des Guyanes: signatures géochimiques et thermochronologiques au transamazonien (2250-1950Ma). $\mathrm{PhD}$ thesis, Université Montpellier II - Sciences et Techniques du Languedoc, 305 p.

European Union, 2017. REGULATION (EU) 2017/821 OF THE EUROPEAN PARLIAMENT AND OF THE COUNCIL of 17 May 2017 laying down supply chain due diligence obligations for Union importers of tin, tantalum and tungsten, their ores, and gold originating from conflict-affected and high-ri. Online $2017,24$.

Franklin, J., Bertoni, C., Boudrie, M., Bout, J., Costelloe, D., Lillie, F., Millo, L., Sauvage, J., 2000. The Paul Isnard gold-copper occurrence, French Guiana: the first volcanogenic massive sulphide occurrence in 
the Guiana Shield? In: Sherlock, R., Logan, M.A.V. (Eds.), VMS Deposits of Latin America, Geological Association of Canada, Mineral Deposits Division. Special Publication, pp. 509-542

Gäbler, H.E., Rehder, S., Bahr, A., Melcher, F., Goldmann, S., 2013. Cassiterite fingerprinting by LA-ICP-MS. J. Anal. At. Spectrom. 28, 1247-1255. https://doi.org/10.1039/c3ja50106j

Gäbler, H.E., Schink, W., Gawronski, T., 2020. Data evaluation for cassiterite and coltan fingerprinting. Minerals 10, 1-15. https://doi.org/10.3390/min10100926

Gäbler, H.E., Schink, W., Goldmann, S., Bahr, A., Gawronski, T., 2017. Analytical Fingerprint of Wolframite Ore Concentrates. J. Forensic Sci. 62, 881-888. https://doi.org/10.1111/1556-4029.13373

Giusti, L., 1986. The morphology, mineralogy, and behavior of "fine-grained" gold from placer deposits of Alberta: sampling and implications for mineral exploration. Can. J. Earth Sci. 23, 1662-1672. https://doi.org/10.1139/e86-154

Giusti, L., Smith, D.G.W., 1984. An electron microprobe study of some Alberta placer gold. TMPM Tschermaks Mineral. und Petrogr. Mitteilungen 33, 187-202. https://doi.org/10.1007/BF01081380

Goix, S., Maurice, L., Laffont, L., Rinaldo, R., Lagane, C., Chmeleff, J., Menges, J., Heimbürger, L.E., MauryBrachet, R., Sonke, J.E., 2019. Quantifying the impacts of artisanal gold mining on a tropical river system using mercury isotopes. Chemosphere 219, 684-694. https://doi.org/10.1016/j.chemosphere.2018.12.036

Goldfarb, R.J., Groves, D.I., 2015. Orogenic gold: Common or evolving fluid and metal sources through time. Lithos. https://doi.org/10.1016/j.lithos.2015.07.011

Grant, A.H., Lavin, O.P., Nichol, I., 1991. The morphology and chemistry of transported gold grains as an exploration tool. J. Geochemical Explor. 40, 73-94. https://doi.org/10.1016/0375-6742(91)90032-P

Groen, J.C., Craig, J.R., Rimstidt, J.D., 1990. Gold-rich rim formation on electrum grains in placers. Can. Mineral. 28, 207-228.

Guiraud, J., Tremblay, A., Jébrak, M., Ross, P.S., Lefrançois, R., 2020. Stratigraphic setting and timing of the Montagne d'Or deposit, a unique Rhyacian Au-rich VMS deposit of the Guiana Shield, French Guiana. Precambrian Res. 337, 105551. https://doi.org/10.1016/j.precamres.2019.105551

Hammer, Ø., Harper, D.A.T., Ryan, P.D., 2001. Past: Paleontological statistics software package for education and data analysis. Palaeontol. Electron. 4, 178. 
Harmon, R.S., Hark, R.R., Throckmorton, C.S., Rankey, E.C., Wise, M.A., Somers, A.M., Collins, L.M., 2017. Geochemical Fingerprinting by Handheld Laser-Induced Breakdown Spectroscopy. Geostand. Geoanalytical Res. 41, 563-584. https://doi.org/10.1111/ggr.12175

Helsel, D.R., 2011. Statistics for Censored Environmental Data Using Minitab® and R: Second Edition, Statistics for Censored Environmental Data Using Minitab® and R: Second Edition. John Wiley and Sons, Hoboken, NJ, USA. https://doi.org/10.1002/9781118162729

Kioe-A-Sen, N.M.E., Van Bergen, M.J., Wong, T.E., Kroonenberg, S.B., 2016. Gold deposits of Suriname: Geological context, production and economic significance, in: Geologie En Mijnbouw/Netherlands Journal of Geosciences. Cambridge University Press, pp. 429-445. https://doi.org/10.1017/njg.2016.40

Kolmogorov, A.N., 1933. Sulla determinazione empirica di una legge di distribuzione. Giorn. Inst. Ital. Attuari 4, 83-91.

Kovacs, R., Schlosser, S., Staub, S.P., Schmiderer, A., Pernicka, E., Günther, D., 2009. Characterization of calibration materials for trace element analysis and fingerprint studies of gold using LA-ICP-MS. J. Anal. At. Spectrom. 24, 476-483. https://doi.org/10.1039/b819685k

Launay, G., Sizaret, S., Lach, P., Melleton, J., Gloaguen, E., Poujol, M., 2021. Genetic relationship between greisenization and Sn-W mineralizations in vein and greisen deposits: Insights from the Panasqueira deposit (Portugal). BSGF - Earth Sci. Bull. 192. https://doi.org/10.1051/bsgf/2020046

Legg, E.D., Ouboter, P.E., Wright, M. a., 2015. Small-Scale Gold Mining Related Mercury Contamination in the Guianas : A Review 1-58. https://doi.org/10.13140/RG.2.1.1399.9204

Liu, H., Beaudoin, G., 2021. Geochemical signatures in native gold derived from Au-bearing ore deposits. Ore Geol. Rev. 132, 104066. https://doi.org/10.1016/j.oregeorev.2021.104066

Liu, H., Beaudoin, G., Makvandi, S., Jackson, S.E., Huang, X., 2021. Multivariate statistical analysis of trace element compositions of native gold from orogenic gold deposits: implication for mineral exploration. Ore Geol. Rev. 131, 104061. https://doi.org/10.1016/j.oregeorev.2021.104061

Mackenzie, D.J., Craw, D., 2005. The mercury and silver contents of gold in quartz vein deposits, Otago Schist, New Zealand. New Zeal. J. Geol. Geophys. 48, 265-278. https://doi.org/10.1080/00288306.2005.9515114

Marcoux, E., Milesi, J.P., 1993. Lead isotope signature of early Proterozoic ore deposits in Western Africa: comparison with gold deposits in French Guiana. Econ. Geol. 88, 1862-1879. https://doi.org/10.2113 
Marquez-Zavalia, M.F., Southam, G., Craig, J.R., Galliski, M.A., 2004. Morphological and chemical study of placer gold from the San Luis Range, Argentina. Can. Mineral. 42, 169-182. https://doi.org/10.2113/gscanmin.42.1.169

Martyna, A., Gäbler, H.E., Bahr, A., Zadora, G., 2018. Geochemical wolframite fingerprinting - the likelihood ratio approach for laser ablation ICP-MS data. Anal. Bioanal. Chem. 410, 3073-3091. https://doi.org/10.1007/s00216-018-1007-9

Massey, F.J., 1951. The Kolmogorov-Smirnov Test for Goodness of Fit. J. Am. Stat. Assoc. 46, 68-78. https://doi.org/10.1080/01621459.1951.10500769

Melcher, F., Sitnikova, M.A., Graupner, T., Martin, N., Oberthür, T., Henjes-kunst, F., Gäbler, E., Gerdes, A., Brätz, H., Davis, D.W., Dewaele, S., Groves, D.I., 2008. Fingerprinting of conflict minerals: columbitetantalite ("coltan") ores. SGA News 23, 1-13.

Milési, JP., Lerouge, C., Delor, C., Ledru, P., Billa, M., Cocherie, A., Egal, E., Fouillac, A., Lahondère, D., Lasserre, J., Marot, A., Martel-Jantin, B., Rossi, P., Tegyey, M., Théveniault, H., Thiéblemont, D., Vanderhaeghe, O., 2003. Gold deposits (gold-bearing tourmalinites, gold-bearing conglomerates, and mesothermal lodes), markers of the geological evolution of French Guiana: geology, metallogeny, and stable-isotope constraints. Géologie de la France 2-3-4:257-290

Milési JP, Egal E, Ledru P, Vernhet Y, Thiéblemont D, Cocherie A, Tegyey M, Martel-Jantin B, Lagny P (1995) Les minéralisations du nord de la Guyane française dans leur cadre géologique, Chronique de la Recherche Minière 518, 5-58.

Milidragovic, D., Beaudoin, G., Jackson, S.E., 2016. In-situ trace element characterization of three gold reference materials using EPMA and LA-ICP-MS, Geological Survey of Canada Open File 8096. https://doi.org/10.4095/299097

Moles, N.R., Chapman, R.J., 2019. Integration of Detrital Gold Microchemistry, Heavy Mineral Distribution, and Sediment Geochemistry to Clarify Regional Metallogeny in Glaciated Terrains: Application in the Caledonides of Southeast Ireland. Econ. Geol. 114, 207-232. https://doi.org/10.5382/econgeo.2019.4628

Monnier, L., Lach, P., Salvi, S., Melleton, J., Bailly, L., Béziat, D., Monnier, Y., Gouy, S., 2018. Quartz traceelement composition by LA-ICP-MS as proxy for granite differentiation, hydrothermal episodes, and related mineralization: The Beauvoir Granite (Echassières district), France. Lithos 320-321, 355-377. https://doi.org/10.1016/j.lithos.2018.09.024 
Monnier, L., Salvi, S., Pochon, A., Melleton, J., Béziat, D., Lach, P., Bailly, L., 2021. Antimony in quartz as a vector to mineralization: A statistical approach from five Variscan $\mathrm{Sb}$ occurrences (France). J. Geochemical Explor. 221, 106705. https://doi.org/10.1016/j.gexplo.2020.106705

Paton, C., Hellstrom, J., Paul, B., Woodhead, J., Hergt, J., 2011. Iolite: Freeware for the visualisation and processing of mass spectrometric data. J. Anal. At. Spectrom. 26, 2508-2518. https://doi.org/10.1039/c1ja10172b

Pochon, A., Desaulty, A.M., Bailly, L., 2020. Handheld laser-induced breakdown spectroscopy (LIBS) as a fast and easy method to trace gold. J. Anal. At. Spectrom. 35, 254-264. https://doi.org/10.1039/c9ja00437h

Roberts, R.J., Dixon, R.D., Merkle, R.K.W., 2016. Distinguishing Between Legally and Illegally Produced Gold in South Africa. J. Forensic Sci. 61, S230-S236. https://doi.org/10.1111/1556-4029.12886

Sheskin, D.J., 2020. Handbook of Parametric and Nonparametric Statistical Procedures, Handbook of Parametric and Nonparametric Statistical Procedures. Chapman and Hall/CRC. https://doi.org/10.1201/9780429186196

Smirnov, N. V., 1939. On the estimation of the discrepancy between empirical curves of distribution for two independent samples. Bull. Math. Univ. Moscou 2, 3-14.

Stumpfl, E.F., Clark, A.M., 1965. Electron-probe microanalysis of gold-platinoid concentrates from southeast Borneo. Trans. I.M.M. 74, 933-946.

Townley, B.K., Hérail, G., Maksaev, V., Palacios, C., de Parseval, P., Sepulveda, F., Orellana, R., Rivas, P., Ulloa, C., 2003. Gold grain morphology and composition as an exploration tool: Application to gold exploration in covered areas. Geochemistry Explor. Environ. Anal. 3, 29-38. https://doi.org/10.1144/1467-787302-042

Vanderhaeghe, O., Ledru, P., Thiéblemont, D., Egal, E., Cocherie, A., Tegyey, M., Milési, J.P., 1998. Contrasting mechanism of crustal growth. Geodynamic evolution of the Paleoproterozoic granitegreenstone belts of French Guiana. Precambrian Res. 92, 165-193. https://doi.org/10.1016/S03019268(98)00074-6

Velasquez, A., 2014. Trace element analysis of native gold by laser ablation ICP-MS: A case study in greenstone-hosted quartz-carbonate vein ore deposits, Timmins , Ontario by. University of British Columbia. https://doi.org/10.14288/1.0074329 
von Gehlen, K., 1983. Silver and mercury in single gold grains from the Witwatersrand and Barberton, South Africa. Miner. Depos. 18, 529-534. https://doi.org/10.1007/BF00204496

Watling, R.J., Scadding, C.J., May, C.D., 2014. Chemical fingerprinting of gold using laser ablation-inductively coupled plasma-mass spectrometry (LA-ICP-MS). J. R. Soc. West. Aust. 97, 87-96.

Watling, R.J., Herbert, H.K., Delev, D., Abell, I.D., 1994. Gold fingerprinting by laser ablation inductively coupled plasma mass spectrometry. Spectrochim. Acta Part B At. Spectrosc. 49, 205-219. https://doi.org/10.1016/0584-8547(94)80019-7

Youngson, J.H., Wopereis, P., Kerr, L.C., Craw, D., 2002. Au-Ag-Hg and Au-Ag alloys in Nokomai and Nevis valley placers, northern Southland and Central Otago, New Zealand, and their implications for placersource relationship. New Zeal. J. Geol. Geophys. 45, 53-69. https://doi.org/10.1080/00288306.2002.9514959 


\section{Highlights}

- The Ag content is an excellent proxy to certify the origin of natural gold

- Combination of various geochemical methods is needed to identify unknown gold origin

- Laser-induced breakdown spectroscopy is powerful to identify gold extracted by $\mathrm{Hg}$ 


\section{Declaration of interests}

$\bigotimes$ The authors declare that they have no known competing financial interests or personal relationships that could have appeared to influence the work reported in this paper.

$\square$ The authors declare the following financial interests/personal relationships which may be considered as potential competing interests:

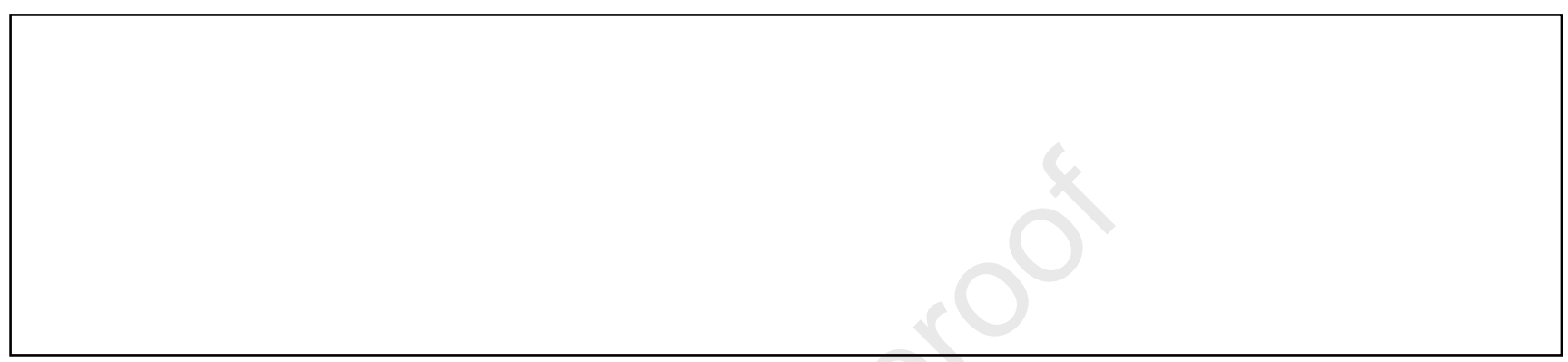

